\title{
Wage Frontiers in Pre \& Post-Crisis Spain: Implications for Welfare and Inequality.
}

\author{
Joanna María Bashford Fernández \\ Oviedo Efficiency Group, University of Oviedo \\ bashfordjoanna.uo@uniovi.es \\ Ana Rodríguez-Álvarez* \\ Oviedo Efficiency Group, University of Oviedo \\ ana@uniovi.es
}

\begin{abstract}
This paper explores the evolution of wages in Spain using a stochastic frontier approach (SFA) to estimate the wage frontiers of workers in Spain as a function of their human capital (education, experience and occupation), year and region. Once the wage frontier has been estimated an analysis is made of determinants (type of contract, economic cycle, gender and region), which may contribute to the workers having difficulties in achieving their maximum attainable potential salary. Given our specific interest in comparing wages before and after the crisis, we monitor the effect on hourly wage of changes in the level of Spanish Gross Domestic Product for the period 2004-2015. For this purpose, a panel data model (Greene, 2005) is used to estimate the stochastic frontier. The data is obtained from the Spanish Living Conditions Survey. Coinciding with three waves (2004-2007, 2008-2011 and 2012-2015) of the SCLS, our database conveniently encompasses differing economic cycles for estimation. Results show that the difficulty of workers in achieving their potential wage is greater at the end of the post-crisis period than the pre-crisis period. Whilst serving to throw some light on the potential and real wages available to Spanish workers before and after the onset of the economic crisis, the paper also offers a brief glimpse of the effect on individual welfare and evidence of an increasing trend in inequality in the post-crisis period.
\end{abstract}

Key words: Spanish wages, stochastic frontier analysis, wage gaps, efficiency

J EL classification: C23, J 31, R11, R12.

*Corresponding author: Ana Rodríguez Álvarez, Department of Economics, University of Oviedo, Avenida del Cristo, 33006 Oviedo, Spain; Tel: +34 985104884

Email for correspondence; ana@uniovi.es

The authors acknowledge financial support from the project ECO2017-86402-C2-1-R (Ministry of Economy and Competitiveness) and the project "Oviedo Efficiency Group" FC-15-GRUPIN14-048 (FEDER and Principality of Asturias). 


\section{Introduction}

The objective of this paper is to explore the evolution of wages in Spain over the period 20042015. More precisely, the data used compares said evolution over three specific periods which because of their cyclical nature prove of great interest for study; 2004-2007 (pre-economic crisis), 2008-2011(economic crisis) and 2012-2015 (post-economic crisis).

When referring to wages, the idea is to apply a stochastic frontier technique to measure the differences that arise between a potential wage, i.e. the one that should be obtained for an individual with particular socio-economic characteristics given his/her investment in human capital and the wage actually obtained by said individual in each regional labour market. In tandem, this offers a measure of the distance to the stochastic frontier which grants us an idea of how difficult it is for an individual to attain his/ her maximum wage.

To analyse the difference between actual and potential wages for individuals over a twelve-year period, we estimate a standard Mincer equation for average hourly wage which incorporates human capital variables such as experience, education and occupation. On the other hand, and in order to explain the distance to the wage frontier, Gross Domestic Product (henceforth GDP) is included with a view to explaining the difficulty that individuals may face in attaining their maximum potential wage. J ointly with GDP we include gender, type of contract and region.

One of the key elements of our model is the presence of a variable for GDP, the latter being commonly recognised as one of the primary indicators of variations in a country's economic cycle. Here we monitor it for Spain with interesting results, that serve to ratify the presence of a worldwide phenomenon more pronounced in developed countries related to individual welfare and inequality which we discuss in more detail below. The study of wages has received in the past and continues to attract numerous and diverse studies in academic and institutional circles.

As shown by the International Labour Organization (henceforth ILO), in their 2014-15 edition of the "Global Wage Report" 1 , wages constitute the largest single source of income for households with at least one member of working age in most countries. They also point out that changes in wages and paid employment appear to be the key factors underlying recent trends in inequality. In global terms, the ILO indicates that wage growth has stagnated even lagging behind pre-crisis rates particularly in the case of developed countries. Verdugo (2016) who studies 8 Eurozone countries before and after the Great Recession, reveals that even with a constant labour force composition in terms of education and experience, those countries particularly affected by the crisis (such as Spain) experienced a significant decrease in average wages during the downturn.

The ILO also report that labour productivity - the value of goods and services produced per person employed - continues to outstrip wage growth in developed economies such as Germany, J apan and the United States, this phenomenon continuing a longer trend which briefly paused only during the financial crisis years of 2008 and 2009. The growing gap between wages and productivity has translated into a declining share of GDP going to labour while an increasing share goes to capital, especially in developed economies.

This trend means that workers and their households are getting a smaller share of economic growth and in consequence experience a reduction in welfare. As the ILO suggests in their report, many developed countries such as the United States or the United Kingdom considered as "strong economies" with sound economic indicators in terms of for example GDP, are now, precisely those where individual welfare and equality appear to be following a declining path. Similar concerns to the ILO have been expressed by the International Monetary Fund (IMF) in their 2017 World

\footnotetext{
1 Global Wage Report 2014/15 published by the International Labour Organization at
} http://www.ilo.org/global/research/global-reports/global-wage-report/2014/lang--en/index.htm 
Economic Outlook report ${ }^{2}$ and even more recently by the Centre for Economic Policy Research (CEPR) in a study on the United Kingdom. ${ }^{3}$

Our paper attempts to study regional wages against the backdrop of the aforementioned scenario and in doing so hopes to throw some light on the potential and real wages available to Spanish workers before and after the onset of the economic crisis. This in turn offers a brief glimpse of the effects on individual welfare.

Moreover, given the high heterogeneity of production structures and labour markets across regions in Spain (for example, more than $60 \%$ of covered workers have their wages set by regional agreements), the regional aspect is of particular interest to policy makers given the indirect implications for re-location of industries and jobs within and outside Spain on a more global scale. Because of this, our analysis also focuses on differences in hourly wages at regional level. On the other hand, Governmental Labour Reforms in 2012 may have altered in part the foregoing wage structure. Given that our study covers the years 2004 to 2015, the Spanish wage evolution during this period could prove relevant.

Our contribution is twofold. On the one hand, we extend the wage frontier analysis to cover a longer period of study to observe the evolution of regional wages over three interesting cyclical periods 2004-2007 (pre-crisis), 2008-2011 (crisis) and 2012-2015 (post-crisis) using the harmonized European survey for Spanish Living Conditions. On the other hand, the methodology we apply in this study (a panel data using true-random effects, Greene, 2005 model) permits us to capture unobservable heterogeneity at an individual (worker) level in an adequate way.

Section 2 is dedicated to a literature review. Section 3 describes the theoretical Model for the stochastic frontier Mincer equation. Section 4 develops our empirical panel data model. Section 5 discusses the survey, panel data and variables used. Section 6 analyses the results in three subsections. Section 7 concludes.

\section{Literature Review}

In terms of labour economics, the study of wages both at microeconomic and macroeconomic level has attracted numerous and diverse studies in the economic literature, both in terms of the aspects considered and the empirical treatment granted.

The explanation of differences in wages and observed earnings has traditionally been linked to human capital theory, with papers using as an initial springboard the base equation described in the seminal work of Mincer (1974). Our literature review starts with an analysis of the Mincerian studies and continues with a revision of those international papers using stochastic frontier analysis to study wage differentials, concluding with a more in-depth look at the studies using this methodology for Spain.

Sanroma and Ramos (1999) using the Survey of family budgets (INE4) for 1990-91 conduct one of the first studies to analyse inter-regional wage differences for 50 Spanish provinces, discovering a high degree of heterogeneity. By means of an enlarged Mincerian equation, they study the magnitude of the "territorial effect" on wages. After controlling for individual and job characteristics, they attribute the still substantial provincial wage differentials to the unequal level of prices and the irregular distribution of unemployment between provinces, which is shown to

\footnotetext{
2 International Monetary Fund (2017), World Economic Outlook, October, "Seeking Sustainable Growth: ShortTerm Recovery, Long-Term Challenges". Chapter 2: "Recent Wage Dynamics in Advanced Economies: Drivers and Implications".

3 Weisbrot and Merling (2018). "The UK Economy at the Crossroads". Centre for Economic Policy Research (CEPR) reports at: http://cepr.net/publications/reports/the-uk-economy-at-the-crossroads

${ }^{4}$ Instituto Nacional de Estadística (The National Statistics Institute), Spain.
} 
have a negative effect on wages close to the magnitude estimated by Blanchflower and Oswald (1994).

The paper of García and Molina (2002) also analyses the wage differentials between different Spanish regions using cross-sectional data for 1994 corresponding to the European Community Household Panel (henceforth ECHP). Hedonic wage equations and wage decomposition method are applied, which allows separation of the effects due to characteristics from those due to returns. Results appear to indicate that the bulk of the gender gap is actually due to differences in the endowments of productive characteristics between males and females but that unobservable factors are also responsible for an important portion of the gap (local labour market conditions, productive structure and demographic factors). The variables that exert greatest influence on the characteristic differences are seniority, possessing a university degree, the command of a second language, the sector of activity, the supervisory tasks undertaken and the occupation. With respect to the different returns, the largest differences correspond to remuneration for seniority, a second language, the sector of activity, the working hours and discrimination by gender.

The article of Simón et al (2006) studies the importance of labour market institutions and in particular, collective wage bargaining in shaping regional wage differences in the Spanish labour market. Using microdata from the Spanish Structure of Earnings Survey (henceforth SSES), for 1995 published by INE, their results reveal that there are significant inter-regional wage differences for similarly skilled workers. These differences exist throughout the entire wage structure and can be explained by competitive and non- competitive factors, such as an insufficient competition in product markets. In this context, industry-level collective bargaining plays a major role in accounting for regional wage differences in Spain.

García-Perez and Jimeno (2007) also use the ECHP for the period 1995-2001 to study public sector wage gaps in Spanish regions. Again, they apply a traditional Mincerian approach to their wage equations for the public and private sector where the dependent variable is the set of observable determinants of wages. Results show that sizeable public-sector wage differences exist among regions that are largely attributable to differences in returns and to a lesser extent to differences and selection effects. Regional differences in public sector wage gaps vary across gender, educational levels and occupations and appear to be correlated positively with the level of regional unemployment and negatively with regional labour productivity.

López-Bazo and Motellón (2012), use micro-level data from the extended year 2000 Spanish sample of the ECHP and a Mincerian wage equation to assess the effect of human capital on regional wage differentials. The results for the set of Spanish regions in the form of Autonomous Communities (NUTS 2) confirm that they differ in the endowment of human capital, but also that the return that individuals obtain from it varies sharply across regions. Regional heterogeneity in returns is especially intense in the case of education, particularly when considering its effect on the employability of individuals. These differences in endowment and, especially, in returns to human capital, account for a significant proportion of regional wage gaps.

Coinciding with the present paper, Hernández and Serrano (2012) use the first wave of the Living Conditions Survey (2004 to 2009), albeit with different methodology to our study, to examine the effect of over-education and its effects on regional wages in Spain. They analyse the wage gaps by region by way of standard Mincer equations, quantile regressions and the Oaxaca-Blinder decomposition. Their findings indicate that a $28 \%$ difference exists between the gross hourly wage of overqualified and well-matched employees, with 25 percentage points corresponding to individual characteristics and the remaining 3 percentage points to characteristics and the firms in which they are employed.

A more recent study of Murillo-Huertas et al (2017), examines regional differences in the gender wage gap in Spain using matched employer- employee microdata (from the 2002, 2006 and 2010 waves of the SSES), two different econometric decomposition methods and panel data techniques. 
Their findings suggest that Spain shows a significant regional heterogeneity in the size of the raw gap, roughly comparable to cross-country differences observed in the European context. The results from the decomposition analysis show that although the bulk of the gender wage gap in Spanish regions is due to differences in the endowments of productive characteristics between males and females there is still a substantial part of the gap that remains unexplained. The analysis of the causes behind the variation of both, the raw and the unexplained gender wage gap by region highlights that several economic, institutional and demographic elements identified in previous studies analysing international differences in the gender wage gap are also relevant to explain regional differences in the gender wage gap in Spain.

As already mentioned, the focus of this paper is on the estimation of wage frontiers or potential wages for individuals across Spain using Stochastic Frontier Analysis, a technique initially developed by Aigner et al. (1977) and Meeusen and Van den Broeck (1977). At the outset, this methodology was applied to study the technical efficiency of firms in different industries although alternative proposals emerged in the fields of health, education and rapidly extended to labour economics amongst others.

Amongst the former studies and building upon Mincer (1974), a valuable and innovative extension to the labour economics literature on earnings is offered by Lovell (2001) who proposes the use of production frontier methodology. The latter involves the estimation of an earnings or wage frontier which represents the maximum attainable wage, based on an individual's own human capital endowments as well as a series of other individual and market characteristics that may influence earnings. This maximum potential wage constitutes an upper frontier of observations where some individuals will actually manage to reach their frontier whilst others fail to do so positioning themselves below it. The distance to the frontier indicates how far a worker is from their potential wage, after having taken into consideration individual or group characteristics. Furthermore, Lovell (1995) also points out that when a difference between potential and observed wage exists but fails to be taken into account, the estimation of parameters describing technology will be biased. The upshot of the latter is that the information derived via the estimation of wage frontiers tends to prove more accurate than those studies based on the use of average functions.

The difference or gap between the actual and estimated frontier wage is a residual term usually assumed as inefficiency in the job search process, such as incomplete information and research costs. In this regard, Polachek and Robst (1998), among others, reveal a consistency between the inefficiency scores obtained via the estimation of the wage frontier and the direct measure of labour market knowledge exhibited by the individuals searching for a job in the study. Similarly, Hofler and Polacheck (1985) employ this method for the first time to study the existence of imperfect information and measured its effect on workers' actual wages. Hofler and Murphy (1992) again apply this technique in a discussion about "underpayment" in the job market.

Aside from the afore-mentioned job search inefficiencies, the aspect which appears to have attracted the greatest wave of studies is the pay gap caused by differences in race, gender, nationality, demographic/ socio-economic status and education. In an international context, some pioneering papers using stochastic frontier analysis to highlight this issue include papers by Robinson and Wunnava (1989), Hunt-McCool and Warren (1993), Croppenstedt and Meschi (1997), Polachek and Robst (1998), Dawson et al (2001), Salas and Contreras (2003), Lang (2005), Adamchik and King (2007) or J ensen et al. (2010).

In the context of our area of interest, namely the Spanish labour market, relevant studies on wage discrimination by gender using stochastic frontier analysis include Díaz and Sánchez (2011) with the more recent contributions of García-Prieto and Gómez-Castilla (2017) and Perez-Villadóniga and Rodriguez-Álvarez (2017a,2017b).

Several of the aforementioned studies are described in more detail below. 
Various studies adopt stochastic frontier methodology to analyse individual country wage structures, focusing frequently in recent years on efficiency or gender aspects of regional wage distributions. For example, Croppenstedt and Meschi (1997) use a random coefficient approach to estimatefrontier earnings functions by gender, marital status and north-south location in order to generate estimates of wage discrimination in Italy. Although overall discrimination is ambiguous they attribute this to a counter-veiling effect of education and tenure. Most married women from the south with secondary or university education are employed in public administration where they are relatively better paid. Results indicate that education rather than the sector of activity is responsible for removing discrimination. A crowding-in hypothesis is also revealed whereby southern-married males earn less if they work in sectors with greater female presence.

Salas and Contreras (2003), conduct a stochastic frontier approach to estimate efficiency measures of the transformation of human capital into earnings in the labour market of Chile for the period 1957-1998. They attribute a mean efficiency of 75\% to the period and an improvement in the levels of efficiency over time. Interestingly, they monitor the co-movements of the rate of growth of GDP and inefficiencies for the years studied in a similar way to the present study which, as explained further on, considers the evolution of GDP and mean efficiency for the period 20042015.

Using the argument that human capital endowments identify earning potentials rather than actual earnings, Lang (2005) uses a stochastic frontier approach to analyse systematic differences in wages between immigrant and native workers in Germany in terms of distance to the frontier. Using the German Socio-Economic Panel (GSOEP) Data of the year 2000, the study reveals that both groups, natives and immigrants, are in fact at about the same distance from the frontier and he concludes that human capital differentials are the most important source of wage inequality.

Adamchik and King (2007), in turn, apply a stochastic frontier approach in order to analyse labour market efficiency in Poland with wage efficiency defined as the ratio of a worker's actual and potential (maximum wage), given his or her demographic and socio-economic characteristics. Their study indicates that in 2001 using data based on the Labour Force Survey conducted by the Polish Central Statistical Office in May of the same year, on average, full-time hired polish workers realized $86 \%$ of their potential earnings. Whilst the identification of the determinants of wage efficiency produced mixed results they concluded that worker performance in Poland is rewarded appropriately by a standard of wage efficiency close to the wage frontier.

Drawing international comparisons, Díaz and Sánchez (2011), analyse the gender wage gap in Germany, France, Italy, Spain and United Kingdom. With data from the ECHP database covering the period 1995-2001 the authors adopt a stochastic frontier approach to study the wage differentials due to gender, after controlling for human capital and other individual characteristics. The authors found support for wage discrimination against women. The results show that a significant part of the gender wage gap in all the countries analysed is not attributable to differences in human capital endowment or personal and job-related characteristics. For Spain, results reveal a potential female wage which is circa $34 \%$ lower than that of males marking a notably greater wage gender gap than for the other countries studied.

Applying a stochastic frontier technique, Contreras et al (2016), conduct a similar analysis to measure the differences that arise between the potential wage, the one that should be obtained for an individual with particular socio-economic characteristics given his/her investment in human capital and the wage actually obtained in the labour market. Once more the data comes from the ECHP for the same period 1995-2001 but only three of the previous study's object countries Germany, United Kingdom and Spain are considered. Here the results indicate that geographical mobility enables men to get closer to their potential wage whereas for women job mobility is influenced by personal and household-related factors which tend to move them away from their potential wage. 
Fewer studies adopt stochastic frontier techniques to study wages focusing only on Spain.

Ahamdanech-Zarco et al (2009) study Spanish labour market efficiency during the period 19952002, marked by labour market reforms and high, but rapidly declining unemployment. Using a stochastic frontier model with data from the Wage Structure Survey they find that female workers, temporary workers, immigrants, the unskilled, service workers, and older workers are relatively inefficient in capturing the returns to their human capital. Overall, the authors reveal a uniform reduction in labour market efficiency between 1995 and 2002.

Ahamdanech-Zarco et al (2011) examines wage inequality in the Spanish labour market from a regional perspective, drawing on stochastic dominance techniques. The field of study is of particular interest because wage determination in Spain incorporates an important territorial component, facilitated by certain specific institutional elements, given that Spain is one of the few developed countries in which collective bargaining is mainly developed through industry-wide agreements on an infra-national scale applied exclusively to provinces or regions. The main empirical findings are that wage inequality exhibits significant regional heterogeneity and that both regional differences in workforce heterogeneity and the mix of jobs and workplaces and differences in their wage returns are influential factors in the explanation of regional heterogeneity in the levels of wage inequality. Additionally, in Spain the regional dimension of collective bargaining at industry level implies the presence of wage determination mechanisms that are differentiated by region, which in turn give rise to the existence of significant differences in regional wage structures.

García-Prieto and Gomez-Castilla (2017) explore gender wage discrimination in Spain and its link to education using a stochastic frontier approach to show that gender discrimination is found to be a less serious problem for more highly educated women. The stochastic frontier approach is employed to measure wage discrimination against women using Spanish data from the European Union Statistics on Income and Living Conditions. The afore-mentioned technique allows the authors to split the gender wage gap of workers displaying the same characteristics into two components: the first measures inefficiency in the job search process caused by imperfect information or gender differences concerning preferences regarding working conditions, whereas the second takes account of discrimination. The study reveals a significant level of discrimination in the Spanish labour market at all educational levels, but this problem is quantitatively more pronounced in the case of less-educated workers, with lower gender discrimination for highly educated women.

Using a stochastic frontier model, Perez-Villadóniga and Rodriguez-Álvarez (2017a), analyse wage differentials for those workers wishing to maximize the return to human capital investment. They propose a new theoretical model where it is the workers themselves who decide the amount they wish to invest in human capital, taking into account the costs of acquiring those skills, for the purpose of maximizing earnings. The empirical implementation of their theoretical model allows the authors, under certain assumptions, to obtain consistent estimates even under theassumption of endogeneity. They present an empirical application to the education sector using data from the Spanish Structure of Earnings Survey 2010. Their results reveal that females and workers in the private education sector face more difficulties in achieving their maximum potential wage.

Perez-Villadóniga and Rodriguez-Álvarez (2017b) again use a stochastic frontier approach to measure the gender gap, both in terms of gross wages and the specific salary component in the form of the base wage, determined by collective bargaining. The wage frontier estimated with data from the 2010 Spanish Structure of Earnings Survey analyses the difference between workers' observed wages and their potential wage, given human capital endowments, as well as firm characteristics. Additionally, the distance to the frontier is measured as a function of workers' gender, to test whether women fail to achieve potential wages to any great extent. 


\section{A Model for the stochastic frontier Mincer equation.}

Aigner et al (1977) consider the fact that the frontier itself might be stochastic. In particular, as explained in more detail below, the stochastic frontier is modelled with a composite disturbance term in the earnings equation. One component of this disturbance is assumed to be normally distributed with zero mean and represents the specification and measurement error, and the other component is assumed to be a random variable with a non- positive distribution. In other words, apart from the term measuring the distance to the frontier, stochastic frontiers include a random error component, which permits the incorporation of the statistical noise common to economic data (see for example, Kumbhakar and Lovell, 2000).

In this paper, we follow the Mincer (1974) approach, where we denote $\mathrm{f}(\mathrm{M})$ as the Mincer equation which relates human capital and wages. The human capital endowment is the key element for the study of wage formation in a competitive market (Mincer, 1970, 1974, Blaug, 1976, Becker, 1993). In order to explain wages, Mincer introduces human capital by way of education (more education implying a higher wage) and work experience (expecting a parabolic relationship with wages, that is, that the latter increase with work experience to a maximum at which point they start to decline). This is due to the fact that at the start, work experience allows workers to improve their productivity at an increasing rate until a moment is reached when human capital tends to accumulate at a lower rate than its depreciation, thus permitting a possible fall in wages. For this reason, the Mincer wage equations include both variables, work experience and the same variable squared (with the expected sign to be positive in the former case and negative in the latter case). The object of the present study is to estimate a Mincer function applying frontier techniques. In order to explain the Mincer-based stochastic frontier equation, an inequality is used which allows the differentiation of observed and maximum (or potential) wage over time in the following manner:

$$
W_{i t} \leq A \exp f\left(M_{i t}, \beta_{i t}\right)
$$

Where W are actual or observed earnings; $\mathrm{A}$ is a constant; $f\left(M_{i t}, \beta_{i t}\right)$ is the Mincer function where $\beta$ is a set of parameters to be estimated; $i$ are individuals (workers) and t is time.

In order to contrast the model, the aforementioned inequality is transformed into an equality:

$$
W_{i \underline{t}}=A \exp f\left(M_{i \underline{t}}, \beta_{i \underline{t}}\right) \exp \left(v_{i \underline{t}}-u_{i t}\right)
$$

Where the error term has two components: the term, $v_{i \underline{t}}$ which is a random disturbance term and $u_{i t}$, that allows the observed wage of any worker to fall short of the maximum potential wage level (the negative sign means that all workers have to be on the frontier or below it). This potential wage is determined not by the deterministic Mincer function frontier $A \exp f\left(M_{i t}, \beta_{i t}\right)$ but by the stochastic wage frontier $A \exp f\left(M_{i t}, \beta_{i t}\right) \exp \left(v_{i t}\right)$. In this way, random differences (captured by $\mathrm{v}_{\mathrm{i}}$ ) are not confused with systematic differences between potential and observed wages (captured by $u_{i t}$ ).

By rearranging Equation (2) we obtain the efficiency of the individual in obtaining his/ her potential wage:

$$
\frac{W_{i t}}{A \exp f\left(M_{i t}, \beta_{i t}\right) \exp \left(v_{i t}\right)}=\exp \left(-u_{i t}\right)=E F F_{i t}
$$


Where $\mathrm{EFF}_{\mathrm{it}}=\exp \left(-u_{i t}\right)$ indicates the difference between the observed and the potential wage for worker $i$ in the period $t$, that is to say, the efficiency term that takes values between 0 and 1 , given that $u_{i t}$ is non-negative.

Once logarithms of Equation (2) are taken, we obtain:

$$
\begin{aligned}
& \ln W_{i t}=\beta_{0}+f\left(M_{i t}, \beta_{i t}\right)+v_{i t}-u_{i t} \\
& \text { Where } \beta_{0}=\ln \mathrm{A} .
\end{aligned}
$$

Our empirical panel data model is developed in the next section.

\section{Empirical Panel Data Model}

In line with the literature available on frontier analysis, the present paper uses a panel data model approach based on Greene (2005) to define a Mincer (1974) equation via the estimation of a timevarying stochastic frontier Normal-Half Normal model with unit-specific intercepts for each of the three 4 year cycles. This particular specification allows separating time-varying inefficiency from unit specific time invariant unobserved heterogeneity. Because of this, Greene terms these models as "true" fixed (TFE) or random-effects (TRE), based on certain assumptions related to unobserved unit-specific heterogeneity, TRE being the model chosen for this paper. Moreover, we allow heteroscedasticity in the variance of the error term. To do this, we employ an empirical specification based on the models of Caudill and Ford (1993), Caudill et al (1995) and Hadri (1999).

Developing the Mincer Equation (4), formally we finally have:

$$
\begin{array}{r}
\ln W_{i t}=\beta_{0}+\beta_{1} \operatorname{Exp}_{i t}+\beta_{11}(\operatorname{Exp})_{i t}^{2}+\beta_{2} E d_{i t}+\sum_{t+1}^{T} \beta_{t} D_{t} \\
+\sum_{A C=2}^{17} \beta_{A C} D_{A C}+\sum_{O c c=2}^{10} \beta_{O c c} D_{O c c}+v_{i t}-u_{i t}
\end{array}
$$

s.t.

$$
\begin{gathered}
v_{i t} \sim N\left(0, \sigma_{\text {vit }}^{2}\right) \\
u_{i t} \sim N^{+}\left(0, \sigma_{\text {uit }}^{2}\right) \\
\sigma_{\text {uit }}^{2}=\exp \left(\boldsymbol{h}_{i}^{\prime}, \phi\right) \\
\boldsymbol{h}_{i}^{\prime}=\left(D_{\text {cont }}, D_{\text {gender }}, D_{A C}, G D P\right)
\end{gathered}
$$

Where $\mathrm{W}=$ the hourly wage of the individual, $\mathrm{i}=$ individual, $\mathrm{t}=$ time $(\mathrm{t}=2004 . .2015)$, Exp $=$ work experience in years, $(\text { Exp })^{2}=(\text { work exp erience in years })^{2}, E d=$ education in years. We have 
included dummies: $D_{t}=$ time dummy by year ; $\mathrm{D}_{\mathrm{AC}}=$ the 17 Autonomous Communities of Spain dummies and $\mathrm{D}_{\mathrm{Occ}}=$ the type of occupation. In Equation (9) we have also included $D_{\text {Cont }}=$ type of contract dummy (temporary or fixed), $D_{\text {gender }}$ and GDP =gross domestic product of Spain.

As we have already explained, the error term has two components: the term $v_{i t}$, which is a normally distributed random disturbance term representing measurement and specification error, and a one-sided disturbance $u_{i t}$, representing worker inefficiency. The latter allows the observed wage of any worker to fall short of the maximum potential wage level (the negative sign meaning that all individuals have to be on the frontier or below it).

$W_{i t}$, the hourly wage of individual $i$ at time $t$, depends on the individual's human capital endowments. In order to proxy human capital and hence, productivity, the individual's education (Ed), experience in the labour market (Exp) and the latter's square, are included. Moreover, occupational dummies which are especially relevant to proxy worker's productivity are included for 10 basic occupational categories. Regional dummies are included to capture the effect which the characteristics of a particular Autonomous Community may have on an individual's wage. Finally, the time dummies will pick up the effect on wages that are characteristics specific to each year, these remaining constant over each four-year cycle.

With reference to equations (8) and (9) these reflect an approach used by the authors previously cited which analyses the effects of several determinants on the variance of the $u$ term. Thus, this model allows heteroscedasticity in $u_{i t}$. In this paper, the determinants (here, type of contract, GDP, gender and Autonomous Communities) of inefficiency $\sigma_{\text {uit }}^{2}$ are included in vector $\boldsymbol{h}_{i}^{\prime}$ (equation 9) following the formulation of Caudill and Ford (1993) and Caudill et al (1995). In this way, we incorporate a dummy related to the type of contract, fixed indefinite or temporary, given that this may affect the hourly wage of an individual. Gross domestic product is included to capture the cycle. On the other hand, we include gender because due to social and cultural constraints, it is possible that women perform worse than men in terms of achieving their potential wage. Lastly, we have also included regional dummies in Equation (9) to explain differences among regions.

\section{Data}

We use data from the 2004-2015 waves of the Spanish Living Conditions Survey (SLCS). The SLCS is a relatively new source of statistical information in the European Union that strengthens the current European statistical infrastructure as a response to the Commission's needs to obtain initial information on the distribution of income and social exclusion in Europe. In doing so it acts as a base for the formulation of its social policy in different spheres, and assists monitoring the effects of these policies in the whole of the European Union (EU). Between 1994 and 2001, the European Union Household Panel (EUHP) survey had satisfied these political needs. Nevertheless, given the need to update its content in view of the new demands, and to improve its functioning (especially as regards the speed at which data is produced), the EUHP was replaced with the SLCS. The target population comprises persons who are members of private households living in mainly family dwellings. Although persons of all ages are part of the target population, all persons are not exhaustively researched since those selected must be aged 16 or over on December 31st of the year prior to the interview in order to respond to the questionnaire. This survey contains personal and labour market characteristics, such as wage, hours worked, age and occupation among other variables. Also, the survey chooses an independent and representative 
sample for each region (in Spain, Autonomous Community) which is an important feature of the survey in terms of our own objectives.

The data is available from the Instituto Nacional de Estadistica (INE), with specific use being made of the longitudinal microdata files for wave 2004-2007 and wave 2008-2011 (both base 2004) and 2012-2015 (base 2013) ${ }^{5}$. The datasets used for the estimation include 59,973 observations for the period 2004-2015. In terms of the data, as far as we are aware, this is the first paper to use this data for the methodology proposed (see Section 5 below) and over the three 4year wave periods. Our descriptive statistics are shown in Table I.

Our dependent variable is gross hourly wage. We proxy human capital by means of experience, education and occupation. Potential labour experience may be estimated as the difference between the age of the employee and the age at which he/she commences work. As regards education, we have detailed information on workers' highest successfully completed level of education, which is then transformed into years of schooling. Hence, education is a proxy for the number of years corresponding to the highest level of education completed by each worker. Moreover, in addition to education and experience, the model incorporates occupation as an additional proxy to the human capital endowment of workers.

Our continuous variables include gross hourly wage per hour, work experience, years of education and GDP, the latter reflecting the \% change for the Spanish economy for the period studied. Gross hourly wage in euros ranges from a minimum of 0.043 in the first wave to 0.01 in the last wave. Notably however, the opposite is true for the maximum hourly wage which stood at 231.94 euros in the first wave, ending at 341.20 euros in the last wave. Over the period the maximum individual work experience declines from 63 years for the period 2004-2007 to 59 years for the period 20122015. Maximum years of education stand at 19 years for each panel.

We include a set of dummies for time, region and occupation. On a regional basis, the $\%$ share of the individuals included in each survey by Autonomous Community is by wave similar with the exception of Madrid in the first period that has a $7 \%$ share of the survey compared with circa $12 \%$ in the next two waves. In terms of gender, the share of individuals is between 52 and $58 \%$ for men and between $42 \%$ and $48 \%$ participation for women. For the period fixed indefinite contracts for individuals interviewed ranged from between $73 \%$ to $79 \%$ of total contracts whilst temporary contracts constituted from between $20 \%$ to $27 \%$. With respect to the occupations of interviewees, the mix changes over the 12-year period. Whilst in the first wave of the survey group 7 representing Craft and related trade workers was the largest group, in the second wave the largest occupational group is group 2 representing Professionals. In the third wave of the survey the largest occupational group is group 5 comprising Services and Sales workers. An explanation of the ISCO-08 international classification provided by the International Labour Organization and used by the survey as well as our own classification for estimation purposes is provided in table if.

\section{Results}

\section{a) Results for the stochastic frontier Mincer Equation (see Table II)}

The results have been obtained via the econometric package Stata 14. The estimates of the Mincer equations are shown in Table I, with a brief review of the results as follows.

\footnotetext{
5 Instituto Nacional de Estadística, Living Conditions Survey/Results/Microdata/Longitudinal files base 2004 and 2013.

http://www.ine.es/dyngs/INEbase/en/operacion.htm?c=Estadistica C\&cid=1254736176807\&menu=resultad os\&secc $=1254736195153 \& i d p=1254735976608$
} 
In terms of Exp, which is in reality a semi-elasticity of how wages vary with changes in work experience, the coefficients are positive and statistically significant at the $1 \%$ level for each of the three panels, albeit exhibiting a similar trend for the pre-crisis and crisis waves and a drastic decline in the post-crisis period. This means that increasing work experience by one year served to boost an individual's wage by $2.24 \%$ in the period 2004-2007, $2.23 \%$ in $2008-2011$ and by a much smaller increase of $0.78 \%$ in the period $2012-2015$. The latter result may reflect the fact that despite Spain's emergence from the crisis wages have not recuperated and possessing work experience has a more diluted effect on individual wages.

Likewise, the variable $(\operatorname{Exp})^{2}$ reflects thefact that an additional year of work experience increases wages. The first two waves exhibit negative coefficients which are statistically significant at the $1 \%$ level for each panel. For the period 2012-2015 the coefficient is zero and statistically insignificant.

As expected the coefficients for the variable Ed are positive and significant at the $1 \%$ level for each period. In the pre-crisis period 2004-2007 an additional year of education boosted an individual's wage by $2.34 \%$, with a slightly smaller increase of $2.28 \%$ registered in the period coinciding with the crisis. It is worth mentioning that the middle wave is likely to offer mixed results given that it incorporates the years of the slump and the partial recovery of late 2010. The most salient result is that for the period 2012-2015 which whilst bearing a positive coefficient, indicates a reward to wages based on an additional year of education, of only $1.53 \%$. The latter period is noteworthy for the major labour reform exercised by the Spanish Government in mid-2012 which together with the high level of unemployment may have served to reduce wages.

The coefficients of the time dummies (all significant at the 1\% level) reflect differing tendencies depending on the cycle. During the pre-crisis cycle salaries display an increasing trend i.e. in 2007 salaries increased $11.56 \%$ with respect to the base year 2004. In the second period, and with respect to the base year 2008, we observe an increase of $2.27 \%$ and $6.63 \%$ for the years 2009 and 2010 respectively, closing the cycle with a smaller increase of $4.73 \%$ in 2011. In contrast to what one might expect in a period of economic recuperation, the wage scenario in the third cycle sees a serious reverse with respect to the base year 2012 with salaries decreasing by $4.25 \%$ and $3.56 \%$ and 2.59\% respectively in 2013, 2014 and 2015. Coinciding with an upturn in Spain's GDP, 2013 appears to signal a deceleration of this downward wage movement.

Given the heterogeneity of Spain Autonomous Communities we consider appropriate the inclusion of regional dummies representing the latter in order to capture these differences in the model. The estimation was made using Madrid as the reference Autonomous Community. Regional results indicate that the Foral Community of Navarra is the only region which registered higher wages than Madrid in the period 2004-2007 with a positive coefficient of 0.11 statistically significant at the $1 \%$ level. Catalonia bears a negative coefficient of 0.0048 which given its nonsignificance suggests that the wage differential between their Autonomous Community and Madrid is negligible (similar results being obtained in the second and third cycles). A comparable situation exists for Cantabria, the Basque country and Balearic Islands with small positive coefficients which lack statistical significance. During the 2008-2011 wave, the Basque country and the Foral Community of Navarra registered higher wages than Madrid and in the period 20122015, they are joined by Asturias and Castile and Leon (all four coefficients proving positive and statistically significant).

In terms of the regions with the lowest wages with respect to Madrid, Galicia, Extremadura and the Canary Islands are the worst performers over the 2004-2015 period. In the aftermath of the economic crisis, there is a weak recuperation in salaries with respect to those registered for Madrid in the period 2004-2007. However, nine of the Autonomous Communities Galicia, Aragon, Castile-La Mancha, Extremadura, Community of Valencia, Balearic Islands, Andalusia, Murcia and Canary Islands still offer lower hourly wages (i.e. lower stochastic wage frontiers 
compared to that for Madrid) to individuals (with similar education, work experience) living in their respective regions than during the cycle of the economic crisis.

In terms of occupational dummies, our calculations for the Mincer equations are made using the Major Group 1 classification corresponding to Managers ${ }^{6}$ based on ISCO-08, the latest recent version of the "International Standard Classification of Occupations" produced by the International Labour Organization. Occupational Group 2 (professionals) ${ }^{7}$ are the only group which command higher wages than Group 1 and this is only true for the pre-crisis initial wave. Group 1 includes a broad range of occupations and the denomination of manager could for example, also include a self-employed individual who earns an hourly wage inferior to other occupational categories within Group 1 such as a CEO or skilled professionals belonging to Group 2. In 2004-2007, an individual belonging to Group 2 earned an hourly wage which was $6.18 \%$ higher than a person in occupational Category 1. Although bearing a positive, but reduced coefficient in the 2008-2011 wave, the statistic for Group 2 is not significant suggesting that potentially there is less of a difference between the hourly wage of this occupational group and Group 1, reflecting perhaps a mixture of effects of the slump and recuperation years. However, in the post-crisis wave of 2012-2015, Group 2 occupations now join the other occupational groups to display a negative coefficient of $9.07 \%$ which is statistically significant at the $1 \%$ level. As expected, the worse performing occupational group is Group 9 which represents elementary occupations usually involving the large bulk of unskilled workers. Their hourly wage is consistently negative (with coefficients statistically significant at the $1 \%$ level), throughout the whole period passing from an hourly wage which is $57.4 \%$ lower than Group 1 in the pre-crisis period 2004-2007 to one which is $68.6 \%$ lower for the final 2012-2015 period. The remaining occupational groups all exhibit negative wage spirals, all significant at the $1 \%$ level of significance and notably, all bearing reduced wages relative to group 1 which are lower in the post-crisis period than in the pre-crisis period. In summary, the results indicate that wages have yet to recuperate their pre-crisis levels.

\section{b) Results for the determinants of $\sigma_{\text {uit }}^{2}$ (see Table III)}

Once the function of the Mincer Frontier has been estimated, it is possible to analyse the determinants of the variance of $u_{i t}$ in line with Equation (9). The determinants of inefficiency $\sigma_{\text {uit }}^{2}$ include characteristics related either to the individual or job, these being the type of contract (temporary or permanent), gender, Autonomous Communities and GDP, with dummies included for the first three. Table III shows the results for the determinants of $\sigma_{\text {uit }}^{2}$.

Given similar human capital endowments, these results give an indication of the relative levels of inefficiency experienced by an individual in being able to obtain his/ her potential wage. In other words, it is a measure of the distance of an individual's actual hourly wage to their potential wage on the stochastic frontier given their human capital.

Here one of the determinants of efficiency for the hourly wage is the type of contract, where the benchmark chosen for the dummy variable is a fixed indefinite contract. A fixed indefinite contract offers some measure of job stability and visible progression to an individual and in this context, should facilitate obtaining the right potential wage given that person's human capital characteristics. As can be observed the coefficient for the type of contract dummy bears a positive

\footnotetext{
${ }^{6}$ Managers include the following sub-groups: Chief executives, senior officials and legislators; Administrative and commercial managers; Production and specialized services managers; Hospitality, retail and other services managers

7 Professionals include the following sub-groups: Science and engineering professionals; Health professionals; Teaching professionals; Business and administration professionals; Information and communications technology professionals; Legal, social and cultural professionals.

Source: http://www.ilo.org/public/english/bureau/stat/isco/docs/resol08.pdf
} 
sign which is statistically significant throughout the entire period of study 2004-2015. In other words, the type of contract influences the individual's ability to reach his/her potential wage given a set of human capital characteristics indicating that an individual with a temporary contract has more difficulties than an individual with a fixed contract in attaining his/her potential wage.

The aspect of gender was not incorporated into our estimation of the Mincer equation frontier because there are no a priori reasons to expect that gender may influence productivity, meaning that both men and women should be able to reach the same wage frontier given their human capital. However, due to social and cultural constraints, it is possible that women perform worse than men in terms of achieving their potential wage. This would be the case if, for instance, females tend to be employed in the lowest ranking jobs within each occupational category (PerezVilladóniga and Rodriguez-Álvarez, 2017a). For this reason, we are interested in checking whether, after controlling for human capital endowments and other characteristics of the worker, gender is a significant determinant in explaining the distance to the potential frontier.

Our results indicate that the coefficient Man which denotes the gender determinant of inefficiency shows a negative and statistically significant coefficient over the period 2004-2015. This signifies that over the three cycles, men with similar human capital to women are always at a greater distance from their potential wage frontier than men.

In line with our comments in Section 1 of this paper, we monitor Spanish GDP (as a \% increase), for the 3 cyclical periods of our study. In the pre-crisis wave of 2004-2007, GDP displays a negative coefficient which is statistically significant at the $1 \%$ level. Here, the negative coefficient reflects the fact that the distance of an individual's actual wage to his/her potential wage has diminished, that is to say, GDP is essentially improving that person's ability to attain their potential wage, by narrowing the gap between the latter and the actual wage. However, for the waves 2008-2011 and 2012-2015 the coefficient for GDP which is again statistically significant at the $1 \%$ level, adopts the opposite sign becoming positive, indicating that the situation is now reversed and the distance between an individual's actual and potential wage is increasing with a resulting increase in the inefficiency of the hourly wage.

In terms of regions and without going into great detail, the results of hourly wages by Autonomous Communities with respect to Madrid are mixed. With the exception of the positive coefficient of Castile-La Mancha which is in fact statistically insignificant, the remaining Autonomous Communities all display negative coefficients in the pre-crisis period. This means that the wage of an individual with given human capital in a region other than Madrid is closer to his or her potential wage represented by their relative stochastic frontier as compared with Madrid. A positive coefficient denotes an increased distance from the stochastic frontier relative to Madrid meaning that individuals are now further away from their potential wage. Galicia and the Basque country are the only two Autonomous regions which maintain statistically significant coefficients for all three cycles, 10 regions exhibiting statistically non-significant coefficients during the postcrisis period 2012-15, the latter allowing little room for interpretation. The Basque country displays a positive and identical coefficient for the latter two cycles as compared to the negative coefficient of the pre-crisis period suggesting that individuals in that region with given human capital characteristics experienced more difficulty in obtaining their potential wage i.e. the distance from their actual wage to their potential wage has increased relative to a similar individual in Madrid where the gap has narrowed.

This result gives rise to an interesting reflection. On the one hand, as observed in Table II and as explained in section 6a, the different regions appear to have a lower potential wage (a lower wage frontier) with respect to the reference region, in our case Madrid. The Autonomous Community 
of Madrid (and also Barcelona) ${ }^{8}$ are considered as business and employment hubs and a substantial part of the best human capital is concentrated in these regions. This can therefore explain why potential wages tend to be higher than in other poorer regions

After the frontier has been estimated and once our model controls the possibility of a different frontier for each region, we are in a position to analyse the distance at which workers find themselves from their potential frontier in accordance with equation (9). The results would appear to indicate that given their human capital, workers situated below their frontier and belonging to the richer regions seem to experience more difficulties in reaching their maximum potential wage. The reason could be twofold: on the one hand, as already mentioned, the potential wages of these richer regions are higher and, on the other hand, there are more candidates with similar human capital endowment characteristics. The upshot of the latter is that not all workers can attain work in accordance with their human capital endowment, this resulting in lower wages for those not positioned on their maximum potential wage frontier due to difficulties caused by the competitive effects of the labour market.

On the contrary, in the poorer regions the opposite effect occurs as workers face less competition which helps them to be closer to their specific (regional) potential wage, which as explained previously, is lower than the richer regions.

\section{c) Results of EFF indices by Panel}

In order to illustrate the effect of GDP on wages over the period 2004-2015 we report Figures I and II and Table IV. Figure I tracks the \% change in GDP registered in the Spanish economy for the years 2004-2015. Figure II and Table IV indicate the EFF indices calculated for each year following Equation (3). Here we recall that these indices measure the distance of a worker from their wage frontier and take values between 0 and 1 ( 1 signifying that the worker has obtained their potential wage whilst the further away they are from the value 1 the greater the distance to their potential wage given their human capital).

In the first cycle as the economy increases (see Figure I), EFF indices increase reflecting the fact that the distance of an individual's actual wage to his/ her potential wage diminished. However, in 2008-2011 and 2012-2015, this is reversed with positive coefficients which reflect a widening distance of the gap between actual and potential wages on the frontier. On a region-wide basis despite an apparent recuperation of the economy from the crisis it appears that the gap between the potential wage and the real wage is increasing, thereby making it more difficult for individuals with similar characteristics to attain the former.

As can easily be observed, in the first two cycles movements in GDP more or less move cyclically with mean efficiency. However, from 2012 onwards despite an increase in GDP, mean efficiency of wages adopts a downward trend. i.e. as the economy grows the welfare of individuals in terms of wages has declined.

We further illustrate what appears to be an increasing trend in wage inequality over the period 2004-2015 in Figure III and Table V. In the latter table we calculate the mean EFF indices by hourly wage deciles for the period with the most relevant deciles plotted under Figure III. As can be observed, the upper deciles 8-10, representing the highest incomes in terms of hourly wages are those closest to their respective wage frontiers in terms of efficiency. In fact, their levels of efficiency appear to be increasing over the post-crisis period (2012-20I5). This effect is in contrast

\footnotetext{
${ }^{8}$ In Table II there is no significant difference in the potential wage frontier between Madrid and Barcelona, but these differences do exist between Madrid and other poorer regions such as the Canary Islands or Extremadura.
} 
to the lowest 3 decile groups which after experiencing similar cyclical trends over the pre and crisis period see a steep drop in the TE of their mean hourly wage in 2012 which also appears to flatten out and even decrease at the end of 2015. The upshot is that these lower income groups of individuals are experiencing substantially greater difficulty in attaining their potential wage, this evidencing a growing trend in inequality if we compare them with their higher income counterparts.

Table VI shows the EFF indices by type of gender, contract and region. In terms of gender the efficiency of men in attaining their potential wage is superior to that of women throughout the whole period, albeit the value of the coefficient in tandem with that of women decreases as the period progresses. In the period 2012-2015 whilst men are still more efficient than women in obtaining their potential salary, they are less efficient at doing this than in the wave 2004-2007. Nevertheless, the wage gap appears to remain constant at about $7 \%$ in the three periods analysed.

In Figure IV we have plotted the mean gender EFF indices by hourly wage deciles for the period revealing that whatever the decile men are always more efficient than women in attaining their potential wage. This being said, both genders appear to be more efficient in the lower half of the hourly wage deciles (1-5), suffering a drop at decile 6 which tends to recuperate for the remaining higher income deciles (7-10) albeit not reaching the highest values of mean gender EFF achieved at decile 4 of $83.6 \%$ and $89.1 \%$ for women and men, respectively. This suggests that while a difference exists between women and men, at the lower end of the wage scale, in potentially more basic and less differentiable jobs involving less skills, individuals find it easier to obtain their maximum potential wage.

Likewise, for the three waves and as expected, having a fixed indefinite contract improves the efficiency of an individual with a given human capital endowment as compared to a person with similar characteristics possessing a temporary contract. Again, for both types of contract thevalue of the EFF indices mean adopts a downward direction and notably, the efficiency of temporary contracts falls from a level of $72.7 \%$ in the pre-crisis period to a level of $70.54 \%$ in theyears 2008 2011 dropping by almost $20 \%$ to a level of $56.7 \%$ in $2012-2015$. This is in line with the evidence for Portugal presented in the paper by Fernandes and Ferreira (2017) using linked employeremployee data for the period 2002-2012. Their study suggests that companies in this country resorted to more flexible fixed term (temporary contracts) given the uncertainty unleashed by the 2008-9 crisis. The upshot was workers earning lower wages, the latter being confirmed by empirical research for these types of contracts.

A similar exercise to that performed for gender was performed using the mean EFF indices by hourly wage deciles relating to individuals holding temporary and fixed-term contracts over the period 2004-2015. As shown in Figure V, individuals with fixed term contracts command higher levels of efficiency for all the wage deciles in comparison with those possessing temporary contracts. Interestingly however, individuals on fixed contracts belonging to the lower wage groups (deciles 1-4) are on average, closer to their potential wage frontiers than those in higher wage brackets. Also, noteworthy, is the tendency for individuals on temporary contracts at the higher end of the wage scale (deciles 7-10), to achieve mean levels of efficiency which are on average almost at a par with their fixed-term counterparts. This probably reflects the fact that more specialized, skilled or managerial jobs, command superior hourly wages and there may be less abundance of these higher profile individuals in the labour market, thus closing the wage gap inequality between these temporary and other comparable full-time workers. Likewise, certain

\footnotetext{
${ }^{9}$ Government reforms took place in 2012 aimed at boosting the creation of permanent jobs with fixed contracts and improved conditions for temporary jobs. It is beyond the scope of this paper both in terms of our objective and the database available to us to analyse in detail the effects of the afore-mentioned government reforms. However, our empirical results do suggest that in terms of hourly wage it became more difficult for individuals to attain their potential wage and this proved more accentuated for those workers with temporary contracts particularly in the last cycle where the difference in their EFF indices more than doubles from $10 \%$ to $21 \%$ as compared with full-time workers.
} 
occupations, for example, consultancy, tend to perform projects over determined periods of time and in many instances resort to highly technical specialist staff on a temporary basis.

On a regional basis, in terms of EFF indices the scenario is similar to gender and type of contract in that all the Autonomous Communities display lower efficiencies at the end of the period. In 2004-2005 Galicia ranked top with an index of $82.97 \%$, followed closely by Canary Islands, La Rioja, the Basque Country and the Community of Valencia. Noticeably the major cities Madrid and Barcelona display lower EFF closer to the worse performer Castile-La Mancha with an index of 75.8\%. The cities which the Autonomous Communities of Madrid and Barcelona embrace are considered as business and employment hubs, with an abundance of candidates with similar capital endowment characteristics. The latter may indeed serve to reduce wages because of the competitive effects making it more difficult for individuals to attain their maximum potential hourly wage.

The period 2008-2011 offers a mix of results possibly because these years cover the crisis and recuperation phase of the economy. Madrid, together with Cantabria, Castile and Leon, Castile La Mancha, Foral community of Navarra actually improve EFF. La Rioja is the best performer with a EFF of $82.4 \%$ whilst Andalusia holds the lowest EFF score with a EFF of $74.7 \%$.

However, in the period 2012-2015 the situation changes drastically with none of the Autonomous Communities achieving efficiency scores superior to the EFF of Aragon at 77.15\%. Nevertheless, three regions register EFF indices in the range of 64-69\%, Asturias obtaining the lowest EFF at $64.6 \%$. This being said, none of the Autonomous Communities achieve their 2004-2007 levels of EFF for hourly wages.

\section{Conclusions}

In summary, the study reveals that individuals with a given human capital endowment such as years of education and work experience (characteristics generally accepted in theoretical and empirical literature), working in a determined occupation and living in any of the Spanish regions experienced more difficulty in attaining their potential wage during the post-crisis period than in the pre-crisis period. More precisely, controlling for region, gender and type of contract, the individuals of the survey have more difficulties in achieving their potential hourly wage at the end of the 2012-2015 wave than in the initial wave of the survey.

The merit of our paper lies in the use of a stochastic frontier estimation of the Mincer equation which covers a relevant and extended cyclical period (2004-2015) not only for Spain but most of the world economies. Moreover, the empirical model is based on the true random-effects model (Greene, 2005) which allows us to separate time-varying inefficiency from individual (worker) specific time invariant unobserved heterogeneity. On the other hand, using control dummies for the Autonomous Communities, gender, GDP and type of contract (temporary or permanent), we are able to explain the difficulty that Spanish workers have in attaining their maximum hourly wage based on their human capital endowment. Also, we reveal that this difficulty has increased over the period of time analysed.

Given our interest in the cyclical effect of the Spanish economy for the years of our study, we monitor the effects of GDP on hourly wage, revealing that whilst the economy reveals signs of economic recuperation in the period 2012-2015, the difference between observed and potential hourly wage has adopted a downward and opposite trend. Also, our analysis by hourly wage deciles reveals an increasing trend in inequality for the period 2012-2015. Whilst individuals in the higher hourly wage deciles seem to be commanding seemingly increasing levels of efficiency i.e. they are becoming closer to their wage frontiers, the exact opposite is true for individuals in the lowest deciles who appear to experience ever greater difficulties in attaining their potential wage. In a nutshell, our findings reveal increased inequality in hourly wages. 
The results of our paper should not be considered in isolation to our European neighbours. In a recent report by the Centre for Economic Policy Research, the authors Weisbrot and Merling, (2018) highlight aspects of hourly wages, inequality and welfare, amongst other issues for the UK. Their findings which cover an extended period similar to that of the present study reveal a pattern comparable to our own results for Spain. More precisely in their discussion of inequality, the authors refer to long-term rising inequality with a redistribution of income to the upper percentiles, real hourly median wages which continue to be $5 \%$ below their 2009 peak, both of these accompanied by an increase of persons on the poverty line as well as one of the worse levels of regional inequality in the European Union. And all of this in the face of a scenario with one of the lowest rates of unemployment in the European Union. As regards hourly earnings by sex, there also appears to be a narrowing of the gender gap attributable, say the authors, not so much to women "catching up" but to the fact that the wages of males have fallen faster than females since 2009.

All the foregoing serves to ratify the findings of the ILO mentioned in Section 1 and confirm to some extent the lag in the recuperation of hourly wages to pre-crisis levels as well as the elements of inequality present in so many developed economies. If this is the case and referring once again to the ILO Global Wage Report 14/15, insofar as the analysis of our study permits, Spanish individuals and households face an important but unequal welfare loss, in that those individuals belonging to higher income groups fare better than those in lower income groups i.e. growing inequality in attaining potential hourly wages. 


\section{References}

Adamchik, V. and King, A. (2007). “Labor Market Efficiency in Poland: A Stochastic Wage Frontier Analysis". The International J ournal of Business and Finance Research, 1(2), 4151.

Ahamdanech-Zarco, I., Weicker. R., Bishop. J. and Liu, H. (2009). "Labor Market Efficiency in Spain: A Stochastic Frontier Approach". Working paper, Department of Economics. College of Arts and Sciences. East Caroline University. Ecu0906. https://www.ecu.edu/cs-cas/econ/upload/ecu0906.pdf

Ahamdanech-Zarco I., García-Pérez, C. and Simón, H. J . (2011). "Wage inequality in Spain: A regional perspective". ERSA conference papers, ersa11 p1074, European Regional Science Association.

Aigner, D., Lovell, C.A.K. and Schmidt, P. (1977). "Formulation and estimation of stochastic frontier production function models". J ournal of Econometrics, 6 (1), 21-37.

Becker, G. S. (1993): Human Capital: A Theoretical and Empirical Analysis with Special Reference to Education, 3 ${ }^{\text {rd }}$ Edition, New York: National Bureau of Economic Research.

Blanchflower, D. and Oswald, A. (1994). The Wage Curve, The MIT Press, Cambridge (Massachusetts) and London.

Blaug, M. (1976): "The Empirical Status of Human Capital Theory: A Slightly J aundiced Survey", J ournal of Economic Literature, 14 (3): 827-855.

Caudill, S., and Ford. J. (1993). "Biases in frontier estimation due to heteroscedasticity". Economic Letters, 41 (1), 17-20.

Caudill, S., Ford, J. and Gropper, D. (1995). "Frontier estimation and firm-specific inefficiency measures in the presence of heteroscedasticity". Journal of Business Economics and Statistics, 13 (1), 105-111.

Contreras, D., Sánchez, R., and Soria, D. (2016). “Geographical Mobility and Wage Efficiency for Women and Men for Four European Countries". Hacienda Pública Española, 216 (1), 6180 .

Croppenstedt, A. and Meschi, M. (1997) "Assessing Wage Discrimination in Italy". Centre for International Business Studies, London Southbank University, Issue 2, working paper No. 11-98, 1-25.

Dawson, P., Hinks, T. and Watson, D. (2001). “German Wage Underpayment: an Investigation into Labor Market Inefficiency and Discrimination". Vierteljahrshefte zur Wirtschaftsforschung, 70, 107-114.

Díaz, M. A. and Sánchez, R. (2011). "Gender and potential wage in Europe: a stochastic frontier approach". International J ournal of Manpower, 32 (4), 410- 425.

Fernandes, A. P., and Ferreira, P. (2017). "Financing constraints and fixed-term employment: Evidence from the 2008-9 financial crisis". European Economic Review, 92, 215- 238.

García, I. and Molina, J. A. (2002). "Inter-regional wage differentials in Spain." Applied Economics Letters, 9 (4), 209-215.

Garcia-Perez, J. I. and Jimeno, J. F. (2007). "Public sector wage gaps in Spanish regions". Manchester School, 75 (4), 501- 531. 
Garcia-Prieto, C. and Gómez-Costilla, P. (2017) "Gender wage gap and education: a stochastic frontier approach". International J ournal of Manpower, 38 (3), 504-516.

Greene, W. (2005). "Reconsidering heterogeneity in panel data estimators of the stochastic frontier model". J ournal of Econometrics, 126 (2), 269- 303.

Hadri, K. (1999). "Estimation of a Doubly Heteroscedastic Stochastic Frontier Cost Function". J ournal of Business Economics and Statistics, 17 (3), 359-363.

Hernández, L and Serrano, L (2012). "Overeducation and its effects on wages: a closer look at the Spanish regions". Investigaciones Regionales, 24, 59- 90.

Hofler, R. A. and Murphy, K. J. (1992), "Underpaid and overworked: measuring the effect of imperfect information on wages". Economic Inquiry, 30 (3), 511-529.

Hofler, R. A. and Polacheck, S. (1985), "A new approach form measuring wage ignorance in the labormarket". J ournal of Economics and Business, 37 (3), 267-276.

Hunt-McCool, J . C. and Warren, R. S. (1993). "Earnings Frontiers and Labor Market Efficiency”. in H. Fried, K. Lovell and S. Schmidt (Eds.), The Measurement of Productive Efficiency: Techniques and Applications, Oxford University Press, 197-209.

International Labour Organization. (2104), Global Wage Report 14/ 15 at http:// www.ilo.org/global/ research/global-reports/global-wage-report/2014/lang-en/index.htm

International Monetary Fund (2017), World Economic Outlook, October, "Seeking Sustainable Growth:Short-Term Recovery, Long-Term Challenges". Chapter 2: "Recent Wage Dynamics in Advanced Economies: Drivers and Implications".

J ensen, U., Gartner, H. and Rässler, S. (2010), "Estimating German overqualification with stochastic earnings frontiers", Advances in Statistical Analysis, 94 (1), 33-51.

Kumbhakar, S. and Lovell, C.A.K. (2000), Stochastic Frontier Analysis, Cambridge University Press.

Lang, G. (2005). "The difference between wages and wage potentials: Earnings disadvantages of immigrants in Germany". J ournal of Economic Inequality, 3 (1), 21-42.

López-Bazo, E., and Motellón, E. (2012). “Human capital and regional wage gaps”. Regional Studies, 46 (10), 1347-1365.

Lovell C.A.K. (1995). "Econometric Efficiency Analysis: A policy-oriented review”. European J ournal of Operational Research, 80, 452-461

Lovell, C.A.K. (2001). "Mirando Hacia Delante: Oportunidades de Investigación Futura en el Análisis de Eficiencia y Productividad, in A. Álvarez Pinilla (Ed.), La medición de la eficiencia y productividad, Editorial Pirámide. Madrid. 331-343.

Meeusen, W. and Van den Broeck, J. (1977), "Efficiency estimation from Cobb-Douglas production function with composed errors". International Economic Review, 18 (2), 435444 .

Mincer, J . (1970): "The Distribution of Labor Incomes: A Survey with Special Reference to the Human Capital Approach", J ournal of Economic Literature, 8 (1): 1-26.

Mincer (1974). Schooling, Experience and Earnings, NBER, 1972, New York.

Murillo-Huertas, I., Ramos, R. and Simón, H. (2017). "Regional Differences in the Gender Wage Gap in Spain”. Social Indicators Research, 134 (3), 981-1008. 
Pérez-Villadóniga, M. J and Rodriguez-Alvarez, A. (2017 a) "Analysing wage differentials when workers maximize the return to human capital investment", Applied Economics, 49 (42), 4196-4208,

Perez-Villadóniga, M.J and Rodriguez-Alvarez, A. (2017b). “Comparing the Gender Gap in Gross and Base Wages". International J ournal of Manpower, 38 (5), 646-660.

Polachek, S. W. and Robst, J . (1998). “Employee Labor Market Information: Comparing Direct World of Work Measures of Workers' Knowledge to Stochastic Frontier Estimates", Labour Economics, 5 (2), 231-242.

Robinson, M. D. and Wunnava, P. V (1989), "Measuring Direct Discrimination in Labor Markets Using a Frontier Approach: Evidence from CPS Female Earnings Data", Southern Economic J ournal, 56 (1), 212-216.

Salas, S., and Contreras, D., (2003). "Chilean Labor Market Efficiency: An Earning Frontier Approach". Estudios de Economía, 3 (1), 87-102.

Sanroma, E., and Ramos, R. (1999). "Interregional wage differences in Spain. A microdata analysis for 1990". J ahrbuch Fur Regionalwissenschaft, 19 (1), 35-54

Simón, H.J , Ramos, R., and Sanromá, E. (2006). “Collective bargaining and regional wage differences in Spain: an empirical analysis". Applied Economics, 38(15), 1749- 1760.

Verdugo, G. (2016). "Real wage cyclicality in the Eurozone before and during the Great Recession: Evidence from micro data". European Economic Review, 82, 46-69.

Weisbrot, M.and Merling, L. (2018). “The UK Economy at the Crossroads”. CEPR reports at http:// cepr.net/ publications/ reports/ the-uk-economy-at-the-crossroads. 
Table I. Descriptive Statistics

Table 1a: Continuous variables

\begin{tabular}{|l|c|c|c|c|c|}
\hline \multicolumn{7}{|c|}{ Pariable } & Obs & Mean & Std.Err. & Min & Max \\
\hline Wage per hour & 18163 & 9.29 & 7.0624 & 0.0431 & 231.94 \\
\hline Work experience & 18163 & 18.10 & 11.8538 & 0 & 63 \\
\hline Years of education & 18163 & 13.84 & 4.0860 & 0 & 19 \\
\hline GDP & 18163 & 3.85 & 0.3502 & 3.2 & 4.2 \\
\hline \multicolumn{5}{|c|}{ Panel $2008-2011$} \\
\hline \multicolumn{1}{|c|}{ Variable } & Obs & Mean & Std. Dev. & Min & Max \\
\hline Wage per hour & 22801 & 11.11 & 8.0549 & 0.0402 & 338.07 \\
\hline Work experience & 22801 & 19.22 & 11.3999 & 0.0 & 60 \\
\hline Years of education & 22801 & 14.42 & 4.0332 & 0.0 & 19.00 \\
\hline GDP & 22801 & -0.99 & 1.5960 & -3.6 & 1.1 \\
\hline \multicolumn{7}{|c|}{ Panel $2012-2015$} \\
\hline Variable & Obs & Mean & Std. Dev. & Min & Max \\
\hline Wage per hour & 19009 & 12.09 & 9.7020 & 0.0102 & 341.20 \\
\hline Work experience & 19009 & 20.85 & 11.2605 & 0 & 59 \\
\hline Years of education & 19009 & 14.77 & 4.0313 & 0 & 19 \\
\hline GDP & 19009 & 0.72 & 2.2414 & -2.9 & 3.2 \\
\hline
\end{tabular}

Table 1b: Time Dummies

\begin{tabular}{|c|c|c|}
\hline Year of survey & Obs & Percent \\
\hline 2004 & 2,761 & 15.2 \\
\hline 2005 & 5,539 & 30.5 \\
\hline 2006 & 7,600 & 41.84 \\
\hline 2007 & 2,263 & 12.46 \\
\hline Total & 18,163 & 100 \\
\hline Year of survey & Obs & Percent \\
\hline 2008 & 3,142 & 13.78 \\
\hline 2009 & 5,413 & 23.74 \\
\hline 2010 & 7,626 & 33.45 \\
\hline 2011 & 6,620 & 29.03 \\
\hline Total & 22,801 & 100 \\
\hline Year of survey & Obs & Percent \\
\hline 2012 & 2,389 & 12.57 \\
\hline 2013 & 4,273 & 22.48 \\
\hline 2014 & 6,466 & 34.02 \\
\hline 2015 & 5,881 & 30.94 \\
\hline Total & 19,009 & 100 \\
\hline
\end{tabular}


Table 1c: Gender

\begin{tabular}{|l|c|c|c|c|c|c|}
\hline \multicolumn{1}{|c|}{ Panels } & \multicolumn{2}{c|}{$2004-2007$} & \multicolumn{2}{c|}{$2008-2011$} & \multicolumn{2}{c|}{ 2012-2015 } \\
\hline Gender & Obs. & Percent & Obs. & Percent & Obs. & Percent \\
\hline Woman & 7,599 & 41.84 & 10,675 & 46.82 & 9,202 & 48.41 \\
\hline Man & 10,564 & 58.16 & 12,126 & 53.18 & 9,807 & 51.59 \\
\hline Total & $\mathbf{1 8 , 1 6 3}$ & $\mathbf{1 0 0}$ & $\mathbf{2 2 , 8 0 1}$ & $\mathbf{1 0 0}$ & $\mathbf{1 9 , 0 0 9}$ & $\mathbf{1 0 0}$ \\
\hline
\end{tabular}

Table 1d: Regions

\begin{tabular}{|l|c|c|c|c|c|c|}
\hline \multicolumn{2}{|c}{ Panels } & \multicolumn{3}{c}{ 2004-2007-2011 } & \multicolumn{2}{c|}{ 2012-2015 } \\
\hline Region & Obs. & Percent & Obs. & Percent & Obs. & Percent \\
\hline Madrid & 1,343 & 7.39 & 2,695 & 11.82 & 2,379 & 12.52 \\
\hline Galicia & 1,172 & 6.45 & 1,505 & 6.6 & 1,254 & 6.6 \\
\hline Principality of Asturias & 684 & 3.77 & 906 & 3.97 & 665 & 3.5 \\
\hline Cantabria & 434 & 2.39 & 677 & 2.97 & 451 & 2.37 \\
\hline Basque Country & 932 & 5.13 & 1,437 & 6.3 & 1,348 & 7.09 \\
\hline Foral Commu. of Navarra & 774 & 4.26 & 861 & 3.78 & 772 & 4.06 \\
\hline La Rioja & 554 & 3.05 & 851 & 3.73 & 601 & 3.16 \\
\hline Aragon & 828 & 4.56 & 1,082 & 4.75 & 891 & 4.69 \\
\hline Castile and Leon & 1,150 & 6.33 & 1,506 & 6.6 & 1,136 & 5.98 \\
\hline Castile-La Mancha & 894 & 4.92 & 1,124 & 4.93 & 726 & 3.82 \\
\hline Extremadura & 698 & 3.84 & 720 & 3.16 & 676 & 3.56 \\
\hline Catalonia & 2,321 & 12.78 & 2,591 & 11.36 & 2,378 & 12.51 \\
\hline Community Valencia & 1,617 & 8.9 & 1,725 & 7.57 & 1,469 & 7.73 \\
\hline Balearic Islands & 803 & 4.42 & 874 & 3.83 & 841 & 4.42 \\
\hline Andalusia & 2,092 & 11.52 & 2,285 & 10.02 & 1,913 & 10.06 \\
\hline Region of Murcia & 899 & 4.95 & 859 & 3.77 & 804 & 4.23 \\
\hline Canary Islands & 968 & 5.33 & 1,103 & 4.84 & 705 & 3.71 \\
\hline Total & $\mathbf{1 8 , 1 6 3}$ & $\mathbf{1 0 0}$ & $\mathbf{2 2 , 8 0 1}$ & $\mathbf{1 0 0}$ & $\mathbf{1 9 , 0 0 9}$ & $\mathbf{1 0 0}$ \\
\hline
\end{tabular}

Table 1e: Type of contract

\begin{tabular}{|l|c|c|c|c|c|c|}
\hline \multicolumn{1}{|c}{ Panels } & \multicolumn{2}{c|}{$2004-2007$} & \multicolumn{2}{c|}{$2008-2011$} & $2012-2015$ \\
\hline Type of contract & Obs. & Percent & Obs. & Percent & Obs. & Percent \\
\hline Fixed indefinite contract & 13,279 & 73.11 & 18,051 & 79.17 & 14,741 & 77.55 \\
\hline Temporary contract & 4,884 & 26.89 & 4,750 & 20.83 & 4,268 & 22.45 \\
\hline Total & $\mathbf{1 8 , 1 6 3}$ & $\mathbf{1 0 0}$ & 22,801 & $\mathbf{1 0 0}$ & $\mathbf{1 9 , 0 0 9}$ & $\mathbf{1 0 0}$ \\
\hline
\end{tabular}


Table 1f: Type of occupation

\begin{tabular}{|l|c|c|c|c|c|c|}
\hline \multicolumn{2}{|c}{ Panels } & \multicolumn{2}{c}{$2004-2007$} & $2008-2011$ & \multicolumn{2}{c|}{$2012-2015$} \\
\hline Type of occupation & Obs. & Percent & Obs. & Percent & Obs. & Percent \\
\hline Managers & 366 & 2.02 & 573 & 2.51 & 458 & 2.41 \\
\hline Professionals & 2,516 & 13.85 & 4,137 & 18.14 & 3,352 & 17.63 \\
\hline Technicians \& associate professionals & 1,891 & 10.41 & 2,361 & 10.35 & 2,415 & 12.7 \\
\hline Clerical support workers & 2,422 & 13.33 & 3,393 & 14.88 & 2,916 & 15.34 \\
\hline Services \& sales workers & 2,831 & 15.59 & 3,809 & 16.71 & 3,450 & 18.15 \\
\hline Skilled,agricultural, forestry \& fishery workers & 252 & 1.39 & 270 & 1.18 & 275 & 1.45 \\
\hline Craft \& related trade workers & 3,234 & 17.81 & 2,821 & 12.37 & 2,074 & 10.91 \\
\hline Plant \& Machine operators \& assemblers & 1,525 & 8.4 & 2,259 & 9.91 & 1,391 & 7.32 \\
\hline Elementary(unskilled) occupations & 2,993 & 16.48 & 3,024 & 13.26 & 2,549 & 13.41 \\
\hline Armed Forces occupations & 133 & 0.73 & 154 & 0.68 & 129 & 0.68 \\
\hline Total & 18,163 & 100 & 22,801 & 100 & 19,009 & 100 \\
\hline
\end{tabular}

Table 1g: Occupational classifications

\begin{tabular}{|l|c|c|}
\hline Type of occupation & (ISCO-08) classification & Our classification \\
\hline Managers & 1 & Occup 1 \\
\hline Professionals & 2 & Occup 2 \\
\hline Technicians \& associate professionals & 3 & Occup 3 \\
\hline Clerical support workers & 4 & Occup 4 \\
\hline Services \& sales workers & 5 & Occup 5 \\
\hline Skilled, agricultural, forestry \& fishery workers & 6 & Occup 6 \\
\hline Craft \& related trade workers & 7 & Occup 7 \\
\hline Plant \& Machine operators \& assemblers & 8 & Occup 8 \\
\hline Elementary(unskilled) occupations & 9 & Occup 9 \\
\hline Armed Forces occupations & 0 & Occup 10 \\
\hline
\end{tabular}


Table II. Mincer Equations estimated for hourly wage

\begin{tabular}{|c|c|c|c|c|c|c|c|c|c|c|c|}
\hline \multirow[t]{2}{*}{ FRONTIER } & \multicolumn{3}{|c|}{ PANEL 2004/2007 } & \multirow[t]{2}{*}{ FRONTIER } & \multicolumn{3}{|c|}{ PANEL 2008/2011 } & \multirow[t]{2}{*}{ FRONTIER } & \multicolumn{3}{|c|}{ PANEL 2012/2015 } \\
\hline & Coef. & t-statistic & Probability & & Coef. & t-statistic & Probability & & Coef. & t-statistic & Probability \\
\hline Exp & 0.0224 & 21.09 & 0.0000 & Exp & 0.0229 & 21.93 & 0.0000 & Exp & 0.0078 & 5.14 & 0.0000 \\
\hline $\operatorname{Exp}^{2}$ & -0.0003 & -12.58 & 0.0000 & $\operatorname{Exp}^{2}$ & -0.0003 & -13.54 & 0.0000 & $\operatorname{Exp}^{2}$ & 0.0000 & -0.92 & 0.3560 \\
\hline Ed & 0.0234 & 19.26 & 0.0000 & Ed & 0.0228 & 18.55 & 0.0000 & Ed & 0.0153 & 10.34 & 0.0000 \\
\hline D2005 & 0.0313 & 3.58 & 0.0000 & D2009 & 0.0227 & 2.64 & 0.0080 & D2013 & -0.0425 & -6.98 & 0.0000 \\
\hline D2006 & 0.0608 & 5.71 & 0.0000 & D2010 & 0.0663 & 9.54 & 0.0000 & D2014 & -0.0356 & -5.43 & 0.0000 \\
\hline D2007 & 0.1156 & 11.23 & 0.0000 & D2011 & 0.0473 & 6.41 & 0.0000 & D2015 & -0.0259 & -3.59 & 0.0000 \\
\hline Galicia & -0.2473 & -9.3 & 0.0000 & Galicia & -0.1888 & -9.24 & 0.0000 & Galicia & -0.1885 & -6.61 & 0.0000 \\
\hline Princ. of Asturias & -0.0534 & -1.72 & 0.0850 & Princ. of Asturias & -0.0260 & -1.03 & 0.3050 & Princ. of Asturias & 0.1383 & 3.16 & 0.0020 \\
\hline Cantabria & 0.0150 & 0.41 & 0.6820 & Cantabria & -0.1233 & -4.43 & 0.0000 & Cantabria & -0.0740 & -1.94 & 0.0520 \\
\hline Basque Country & 0.0279 & 1.01 & 0.3140 & Basque Country & 0.0723 & 3.39 & 0.0010 & Basque Country & 0.3320 & 11.42 & 0.0000 \\
\hline F.C.Navarra & 0.1100 & 3.58 & 0.0000 & F.C.Navarra & 0.0965 & 3.85 & 0.0000 & F.C.Navarra & 0.0905 & 2.28 & 0.0230 \\
\hline La Rioja & -0.0926 & -2.82 & 0.0050 & La Rioja & -0.1106 & -4.44 & 0.0000 & La Rioja & 0.0023 & 0.07 & 0.9480 \\
\hline Aragon & -0.0191 & -0.66 & 0.5070 & Aragon & -0.0363 & -1.54 & 0.1240 & Aragon & -0.0562 & -1.93 & 0.0530 \\
\hline Castile and Leon & -0.0743 & -2.81 & 0.0050 & Castile and Leon & -0.0395 & -1.96 & 0.0500 & Castile and Leon & 0.0590 & 1.76 & 0.0790 \\
\hline Castile-La Mancha & -0.0496 & -1.74 & 0.0810 & Castile-La Mancha & -0.0777 & -3.39 & 0.0010 & Castile-La Mancha & -0.1159 & -3.33 & 0.0010 \\
\hline Extremadura & -0.1715 & -5.6 & 0.0000 & Extremadura & -0.1946 & -7.22 & 0.0000 & Extremadura & -0.2465 & -6.56 & 0.0000 \\
\hline Catalonia & -0.0048 & -0.21 & 0.8330 & Catalonia & 0.0045 & 0.26 & 0.7980 & Catalonia & -0.0106 & -0.41 & 0.6800 \\
\hline C.Valencia & -0.1707 & -6.89 & 0.0000 & C.Valencia & -0.1025 & -5.21 & 0.0000 & C.Valencia & -0.0881 & -3.05 & 0.0020 \\
\hline Balearic Islands & 0.0106 & 0.36 & 0.7180 & Balearic Islands & -0.0266 & -1.05 & 0.2930 & Balearic Islands & -0.0703 & -2.04 & 0.0420 \\
\hline Andalusia & -0.0989 & -4.25 & 0.0000 & Andalusia & -0.0166 & -0.9 & 0.3670 & Andalusia & -0.0849 & -3.21 & 0.0010 \\
\hline R. Murcia & -0.0832 & -2.96 & 0.0030 & R. Murcia & -0.1051 & -4.21 & 0.0000 & R. Murcia & -0.2286 & -7.01 & 0.0000 \\
\hline Canary Islands & -0.1820 & -6.66 & 0.0000 & Canary Islands & -0.1382 & -5.96 & 0.0000 & Canary Islands & -0.2294 & -6.36 & 0.0000 \\
\hline Occup 2 & 0.0618 & 2.26 & 0.0240 & Occup 2 & 0.0334 & 1.32 & 0.1860 & Occup 2 & -0.0907 & -2.75 & 0.0060 \\
\hline Occup 3 & -0.2531 & -9.21 & 0.0000 & Occup 3 & -0.2485 & -9.56 & 0.0000 & Occup 3 & -0.3746 & -10.86 & 0.0000 \\
\hline Occup 4 & -0.3459 & -12.67 & 0.0000 & Occup 4 & -0.3939 & -15.44 & 0.0000 & Occup 4 & -0.4183 & -12.67 & 0.0000 \\
\hline Occup 5 & -0.5128 & -18.6 & 0.0000 & Occup 5 & -0.5218 & -20.29 & 0.0000 & Occup 5 & -0.6398 & -18.95 & 0.0000 \\
\hline Occup 6 & -0.6287 & -15.5 & 0.0000 & Occup 6 & -0.5933 & -14.83 & 0.0000 & Occup 6 & -0.7261 & -14.65 & 0.0000 \\
\hline Occup 7 & -0.4656 & -16.96 & 0.0000 & Occup7 & -0.4524 & -17.16 & 0.0000 & Occup7 & -0.5888 & -16.74 & 0.0000 \\
\hline Occup 8 & -0.4049 & -14.06 & 0.0000 & Occup 8 & -0.4481 & -16.7 & 0.0000 & Occup 8 & -0.5904 & -15.57 & 0.0000 \\
\hline Occup 9 & -0.5739 & -20.65 & 0.0000 & Occup 9 & -0.5814 & -21.92 & 0.0000 & Occup 9 & -0.6855 & -19.63 & 0.0000 \\
\hline Occup 10 & -0.2293 & -4.48 & 0.0000 & Occup 10 & -0.2129 & -4.25 & 0.0000 & Occup 10 & -0.2681 & -3.12 & 0.0020 \\
\hline Constant & 2.0824 & 52.19 & 0.0000 & Constant & 2.2420 & 62.25 & 0.0000 & Constant & 2.7492 & 60.13 & 0.0000 \\
\hline
\end{tabular}

* The reference Autonomous Community is Madrid. As regard occupations, Group 1 (managers) is the reference group. 
Table III. $\sigma_{u}^{2}$ determinants

\begin{tabular}{|c|c|c|c|c|c|c|c|c|c|c|c|}
\hline & \multicolumn{3}{|c|}{ PANEL 2004/2007 } & \multicolumn{4}{|c|}{ PANEL 2008/2011 } & \multicolumn{4}{|c|}{ PANEL 2012/2015 } \\
\hline & Coef. & t-statistic & Probability & & Coef. & t-statistic & Probability & & Coef. & t-statistic & Probability \\
\hline Temporary Contract & 1.2319 & 23.51 & 0.0000 & Temporary Contract & 1.1752 & 26.17 & 0.0000 & Temporary Contract & 2.3895 & 53.57 & 0.0000 \\
\hline GDP & -0.2176 & -2.46 & 0.0140 & GDP & 0.1038 & 7.14 & 0.0000 & GDP & 0.0400 & 4.22 & 0.0000 \\
\hline Galicia & -1.0678 & -5.9 & 0.0000 & Galicia & -0.5757 & -4.57 & 0.0000 & Galicia & -0.2118 & -2.00 & 0.0460 \\
\hline Prin.of Asturias & -0.3763 & -2.04 & 0.0420 & Prin.of Asturias & -0.1341 & -0.96 & 0.3350 & Prin.of Asturias & -0.1838 & -1.31 & 0.1890 \\
\hline Cantabria & -0.2644 & -1.19 & 0.2360 & Cantabria & -0.6416 & -3.7 & 0.0000 & Cantabria & -0.0714 & -0.46 & 0.6480 \\
\hline Basque country & -0.8161 & -4.26 & 0.0000 & Basque country & 0.2092 & 1.88 & 0.0600 & Basque country & 0.2902 & 2.90 & 0.0040 \\
\hline F.C.Navarra & -0.2185 & -1.25 & 0.2100 & F.C.Navarra & -0.2693 & -1.96 & 0.0500 & F.C.Navarra & -0.3903 & -3.10 & 0.0020 \\
\hline La Rioja & -0.8315 & -3.72 & 0.0000 & La Rioja & -0.5606 & -3.8 & 0.0000 & La Rioja & -0.1284 & -0.96 & 0.3360 \\
\hline Aragon & -0.5412 & -2.96 & 0.0030 & Aragon & 0.0417 & 0.34 & 0.7360 & Aragon & -0.4170 & -3.45 & 0.0010 \\
\hline Castile \& Leon & -0.4183 & -2.68 & 0.0070 & Castile \& Leon & -0.5380 & -4.54 & 0.0000 & Castile \& Leon & 0.0433 & 0.40 & 0.6890 \\
\hline Castile-La Mancha & 0.2018 & 1.32 & 0.1880 & Castile-La Mancha & -0.2653 & -2.1 & 0.0360 & Castile-La Mancha & -0.1009 & -0.79 & 0.4300 \\
\hline Extremadura & -0.5700 & -3.06 & 0.0020 & Extremadura & 0.0126 & 0.09 & 0.9280 & Extremadura & -0.1979 & -1.51 & 0.1310 \\
\hline Catalonia & -0.4121 & -3.05 & 0.0020 & Catalonia & 0.0740 & 0.76 & 0.4450 & Catalonia & -0.0117 & -0.13 & 0.8930 \\
\hline C.Valencia & -0.7451 & -4.7 & 0.0000 & C.Valencia & -0.1962 & -1.8 & 0.0730 & C.Valencia & 0.1969 & 2.02 & 0.0430 \\
\hline Balearic Islands & -0.6905 & -3.67 & 0.0000 & Balearic Islands & -0.0612 & -0.44 & 0.6600 & Balearic Islands & 0.0836 & 0.72 & 0.4710 \\
\hline Andalusia & -0.5841 & -4.21 & 0.0000 & Andalusia & 0.3043 & 3.19 & 0.0010 & Andalusia & -0.0195 & -0.21 & 0.8310 \\
\hline Reg. Murcia & -0.3455 & -2.11 & 0.0350 & Reg. Murcia & -0.1365 & -1.02 & 0.3060 & Reg. Murcia & -0.2489 & -2.05 & 0.0400 \\
\hline Canary Islands & -0.9795 & -5.16 & 0.0000 & Canary Islands & 0.1320 & 1.1 & 0.2700 & Canary Islands & 0.1165 & 0.92 & 0.3600 \\
\hline Man & -0.7344 & -13.94 & 0.0000 & Man & -0.5177 & -12.28 & 0.0000 & Man & -0.3673 & -8.86 & 0.0000 \\
\hline constant & -1.5619 & -4.44 & 0.0000 & constant & -2.6242 & -35.81 & 0.0000 & constant & -2.8328 & -42.28 & 0.0000 \\
\hline
\end{tabular}

* The reference Autonomous Community is Madrid. As regard occupations, Group 1 (managers) is the reference group. 
Table IV. Mean EFF indices of hourly wage per \% annual change in GDP

\begin{tabular}{|c|c|c|}
\hline YEAR & TE MEAN & GDP \\
\hline $\mathbf{2 0 0 4}$ & 0.7929 & 3.2 \\
\hline $\mathbf{2 0 0 5}$ & 0.8005 & 3.7 \\
\hline $\mathbf{2 0 0 6}$ & 0.8042 & 4.2 \\
\hline $\mathbf{2 0 0 7}$ & 0.7984 & 3.8 \\
\hline $\mathbf{2 0 0 8}$ & 0.7552 & 1.1 \\
\hline $\mathbf{2 0 0 9}$ & 0.8037 & -3.6 \\
\hline $\mathbf{2 0 1 0}$ & 0.7838 & 0 \\
\hline $\mathbf{2 0 1 1}$ & 0.7950 & -1 \\
\hline $\mathbf{2 0 1 2}$ & 0.7439 & -2.9 \\
\hline $\mathbf{2 0 1 3}$ & 0.7436 & -1.7 \\
\hline $\mathbf{2 0 1 4}$ & 0.7315 & 1.4 \\
\hline $\mathbf{2 0 1 5}$ & 0.7120 & 3.2 \\
\hline
\end{tabular}

Table V. Mean EFF indices of hourly wage by deciles and year

\begin{tabular}{|lllllllllll}
\hline year & decile 1 & decile 2 & decile 3 & decile 4 & decile 5 & decile 6 & decile 7 & decile 8 & decile 9 & decile 10 \\
\hline 2004 & 0.5112 & 0.7078 & 0.7635 & 0.7978 & 0.8289 & 0.8542 & 0.8587 & 0.8789 & 0.9018 & 0.9296 \\
2005 & 0.5073 & 0.7023 & 0.7686 & 0.8058 & 0.8300 & 0.8485 & 0.8695 & 0.8836 & 0.8997 & 0.9279 \\
2006 & 0.4932 & 0.6997 & 0.7694 & 0.8007 & 0.8298 & 0.8527 & 0.8669 & 0.8814 & 0.8972 & 0.9287 \\
2007 & 0.4161 & 0.6904 & 0.7383 & 0.7908 & 0.8062 & 0.8367 & 0.8580 & 0.8742 & 0.8898 & 0.9209 \\
\hline 2008 & 0.4276 & 0.6735 & 0.7487 & 0.7940 & 0.8194 & 0.8345 & 0.8606 & 0.8857 & 0.9001 & 0.9355 \\
2009 & 0.5002 & 0.7040 & 0.7745 & 0.7967 & 0.8270 & 0.8558 & 0.8688 & 0.8878 & 0.9039 & 0.9368 \\
2010 & 0.4401 & 0.6586 & 0.7382 & 0.7730 & 0.8105 & 0.8282 & 0.8501 & 0.8682 & 0.8903 & 0.9281 \\
2011 & 0.4568 & 0.6653 & 0.7397 & 0.7871 & 0.8137 & 0.8404 & 0.8525 & 0.8719 & 0.8922 & 0.9307 \\
2012 & 0.2395 & 0.5011 & 0.6240 & 0.7140 & 0.7773 & 0.8154 & 0.8501 & 0.8834 & 0.9204 & 0.9665 \\
2013 & 0.2481 & 0.5202 & 0.6259 & 0.7283 & 0.7832 & 0.8224 & 0.8588 & 0.8861 & 0.9171 & 0.9678 \\
2014 & 0.2436 & 0.5080 & 0.6293 & 0.7207 & 0.7744 & 0.8188 & 0.8566 & 0.8819 & 0.9242 & 0.9677 \\
2015 & 0.2395 & 0.4913 & 0.6147 & 0.6989 & 0.7571 & 0.8030 & 0.8556 & 0.8782 & 0.9185 & 0.9659 \\
\hline
\end{tabular}


Table VI A. EFF indices by panel (2004/ 2007)

\begin{tabular}{|l|c|c|c|c|c|c|}
\hline PANEL 2004/2007 & Obs & Mean & Std. Err. & \multicolumn{2}{|c|}{ (95\% Conf. Interval) } \\
\hline Woman & 7599 & 0.7570 & 0.0019 & 0.7533 & 0.7608 \\
\hline Man & 10564 & 0.8320 & 0.0013 & 0.8295 & 0.8345 \\
\hline & & & & & \\
\hline PANEL 2004/2007 & Obs & Mean & Std. Err. & (95\% Conf. Interval) \\
\hline Fixed indefinite contract & 13,279 & 0.8279 & 0.0011 & 0.8257 & 0.8301 \\
\hline Temporary contract & 4,884 & 0.7265 & 0.0027 & 0.7213 & 0.7318 \\
\hline & & & & & \\
\hline REGION & Obs & Mean & Std. Err. & (95\% Conf. Interval) \\
\hline Madrid & 1,343 & 0.7719 & 0.0044 & 0.7633 & 0.7805 \\
\hline Galicia & 1,172 & 0.8297 & 0.0040 & 0.8218 & 0.8375 \\
\hline Principality of Asturias & 684 & 0.7976 & 0.0061 & 0.7856 & 0.8095 \\
\hline Cantabria & 434 & 0.7855 & 0.0080 & 0.7698 & 0.8013 \\
\hline Basque Country & 932 & 0.8224 & 0.0047 & 0.8133 & 0.8315 \\
\hline Foral Commu. of Navarra & 774 & 0.7732 & 0.0060 & 0.7614 & 0.7850 \\
\hline La Rioja & 554 & 0.8236 & 0.0055 & 0.8128 & 0.8345 \\
\hline Aragon & 828 & 0.8079 & 0.0052 & 0.7977 & 0.8182 \\
\hline Castile and Leon & 1,150 & 0.8083 & 0.0043 & 0.7998 & 0.8169 \\
\hline Castile-La Mancha & 894 & 0.7577 & 0.0058 & 0.7462 & 0.7691 \\
\hline Extremadura & 698 & 0.7893 & 0.0060 & 0.7775 & 0.8011 \\
\hline Catalonia & 2,321 & 0.7984 & 0.0032 & 0.7921 & 0.8047 \\
\hline Community of Valencia & 1,617 & 0.8182 & 0.0034 & 0.8115 & 0.8250 \\
\hline Balearic Islands & 803 & 0.8115 & 0.0050 & 0.8018 & 0.8213 \\
\hline Andalusia & 2,092 & 0.7949 & 0.0034 & 0.7882 & 0.8017 \\
\hline Region of Murcia & 899 & 0.7855 & 0.0053 & 0.7752 & 0.7959 \\
\hline Canary Islands & 968 & 0.8283 & 0.0041 & 0.8202 & 0.8364 \\
\hline
\end{tabular}


Table VI B. EFF indices by panel (2008/2011)

\begin{tabular}{|l|c|c|c|c|c|c|}
\hline PANEL 2008/2011 & Obs & Mean & Std. Err. & \multicolumn{1}{l|}{ (95\% Conf. Interval) } \\
\hline Woman & 10,675 & 0.7538 & 0.0017 & 0.7505 & 0.7572 \\
\hline Man & 12,126 & 0.8177 & 0.0014 & 0.8150 & 0.8205 \\
\hline & & & & & \\
\hline PANEL 2008/2011 & Obs & Mean & Std. Err. & (95\% Conf. Interval) \\
\hline Fixed indefinite contract & 18,051 & 0.8095 & 0.0011 & 0.8073 & 0.8117 \\
\hline Temporary contract & 4,750 & 0.7054 & 0.0030 & 0.6996 & 0.7113 \\
\hline & & & & & \\
\hline REGION & Obs & Mean & Std. Err. & (95\% Conf. Interval) \\
\hline Madrid & 2,695 & 0.7816 & 0.0032 & 0.7752 & 0.7880 \\
\hline Galicia & 1,505 & 0.8195 & 0.0038 & 0.8120 & 0.8270 \\
\hline Principality of Asturias & 906 & 0.7827 & 0.0054 & 0.7721 & 0.7934 \\
\hline Cantabria & 677 & 0.8137 & 0.0061 & 0.8018 & 0.8257 \\
\hline Basque Country & 1,437 & 0.7673 & 0.0047 & 0.7580 & 0.7766 \\
\hline Foral Commu. of Navarra & 861 & 0.8020 & 0.0055 & 0.7912 & 0.8127 \\
\hline La Rioja & 851 & 0.8236 & 0.0049 & 0.8140 & 0.8332 \\
\hline Aragon & 1,082 & 0.7886 & 0.0051 & 0.7786 & 0.7986 \\
\hline Castile and Leon & 1,506 & 0.8155 & 0.0038 & 0.8079 & 0.8230 \\
\hline Castile-La Mancha & 1,124 & 0.8023 & 0.0047 & 0.7930 & 0.8116 \\
\hline Extremadura & 720 & 0.7739 & 0.0069 & 0.7603 & 0.7876 \\
\hline Catalonia & 2,591 & 0.7784 & 0.0032 & 0.7721 & 0.7848 \\
\hline Community of Valencia & 1,725 & 0.8029 & 0.0038 & 0.7955 & 0.8102 \\
\hline Balearic Islands & 874 & 0.7798 & 0.0056 & 0.7688 & 0.7909 \\
\hline Andalusia & 2,285 & 0.7466 & 0.0040 & 0.7387 & 0.7545 \\
\hline Region of Murcia & 859 & 0.7943 & 0.0055 & 0.7836 & 0.8051 \\
\hline Canary Islands & 1,103 & 0.7770 & 0.0051 & 0.7669 & 0.7871 \\
\hline
\end{tabular}


Table VI C. EFF indices by panel (2012/2015)

\begin{tabular}{|l|c|c|c|c|c|c|}
\hline PANEL 2012/2015 & Obs & Mean & Std. Err. & \multicolumn{2}{|l|}{ (95\% Conf. Interval) } \\
\hline WOMAN & 9,202 & 0.6925 & 0.0025 & 0.6876 & 0.6973 \\
\hline MAN & 9,807 & 0.7647 & 0.0024 & 0.7600 & 0.7694 \\
\hline & & & & & \\
\hline PANEL 2012/2015 & Obs & Mean & Std. Err. & \multicolumn{1}{l|}{ (95\% Conf. Interval) } \\
\hline Fixed indefinite contract & 14,741 & 0.7768 & 0.0017 & 0.7735 & 0.7800 \\
\hline Temporary contract & 4,268 & 0.5673 & 0.0043 & 0.5588 & 0.5758 \\
\hline & & & & & \\
\hline REGION & Obs & Mean & Std. Err. & (95\% Conf. Interval) \\
\hline Madrid & 2,379 & 0.7379 & 0.0048 & 0.7285 & 0.7474 \\
\hline Galicia & 1,254 & 0.7572 & 0.0065 & 0.7445 & 0.7699 \\
\hline Principality of Asturias & 665 & 0.6463 & 0.0093 & 0.6280 & 0.6646 \\
\hline Cantabria & 451 & 0.7308 & 0.0110 & 0.7093 & 0.7524 \\
\hline Basque Country & 1,348 & 0.7071 & 0.0063 & 0.6947 & 0.7194 \\
\hline Foral Commu. of Navarra & 772 & 0.7617 & 0.0079 & 0.7463 & 0.7772 \\
\hline La Rioja & 601 & 0.7362 & 0.0092 & 0.7182 & 0.7543 \\
\hline Aragon & 891 & 0.7715 & 0.0075 & 0.7568 & 0.7861 \\
\hline Castile and Leon & 1,136 & 0.6876 & 0.0070 & 0.6739 & 0.7014 \\
\hline Castile-La Mancha & 726 & 0.7439 & 0.0088 & 0.7267 & 0.7612 \\
\hline Extremadura & 676 & 0.7167 & 0.0100 & 0.6970 & 0.7363 \\
\hline Catalonia & 2,378 & 0.7524 & 0.0047 & 0.7432 & 0.7616 \\
\hline Community of Valencia & 1,469 & 0.7272 & 0.0062 & 0.7150 & 0.7394 \\
\hline Balearic Islands & 841 & 0.7455 & 0.0082 & 0.7294 & 0.7616 \\
\hline Andalusia & 1,913 & 0.6990 & 0.0061 & 0.6869 & 0.7110 \\
\hline Region of Murcia & 804 & 0.7423 & 0.0088 & 0.7251 & 0.7595 \\
\hline Canary Islands & 705 & 0.7259 & 0.0100 & 0.7062 & 0.7456 \\
\hline
\end{tabular}


Figure I.

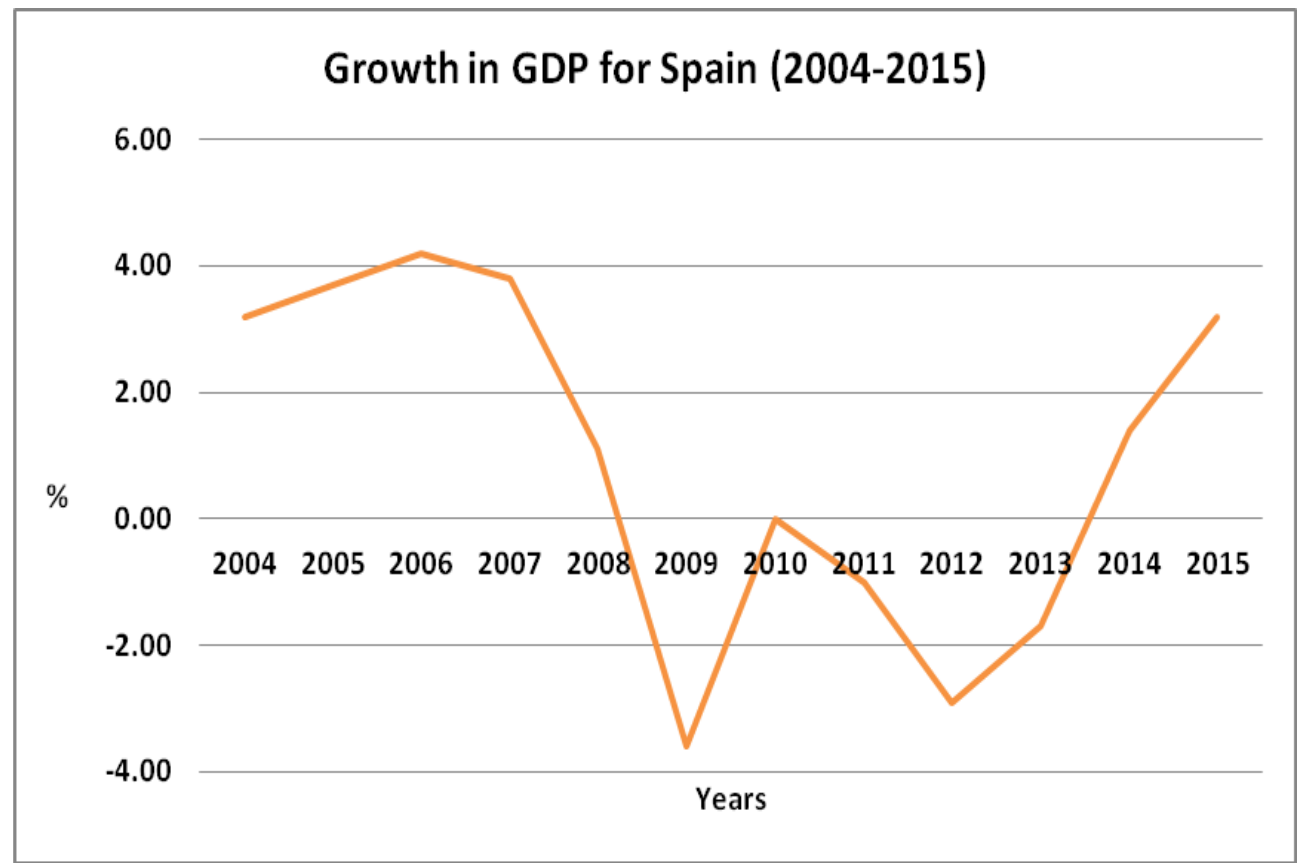

Source of GDP data : http://www.datosmacro.com/pib/espana

\section{Figure II}

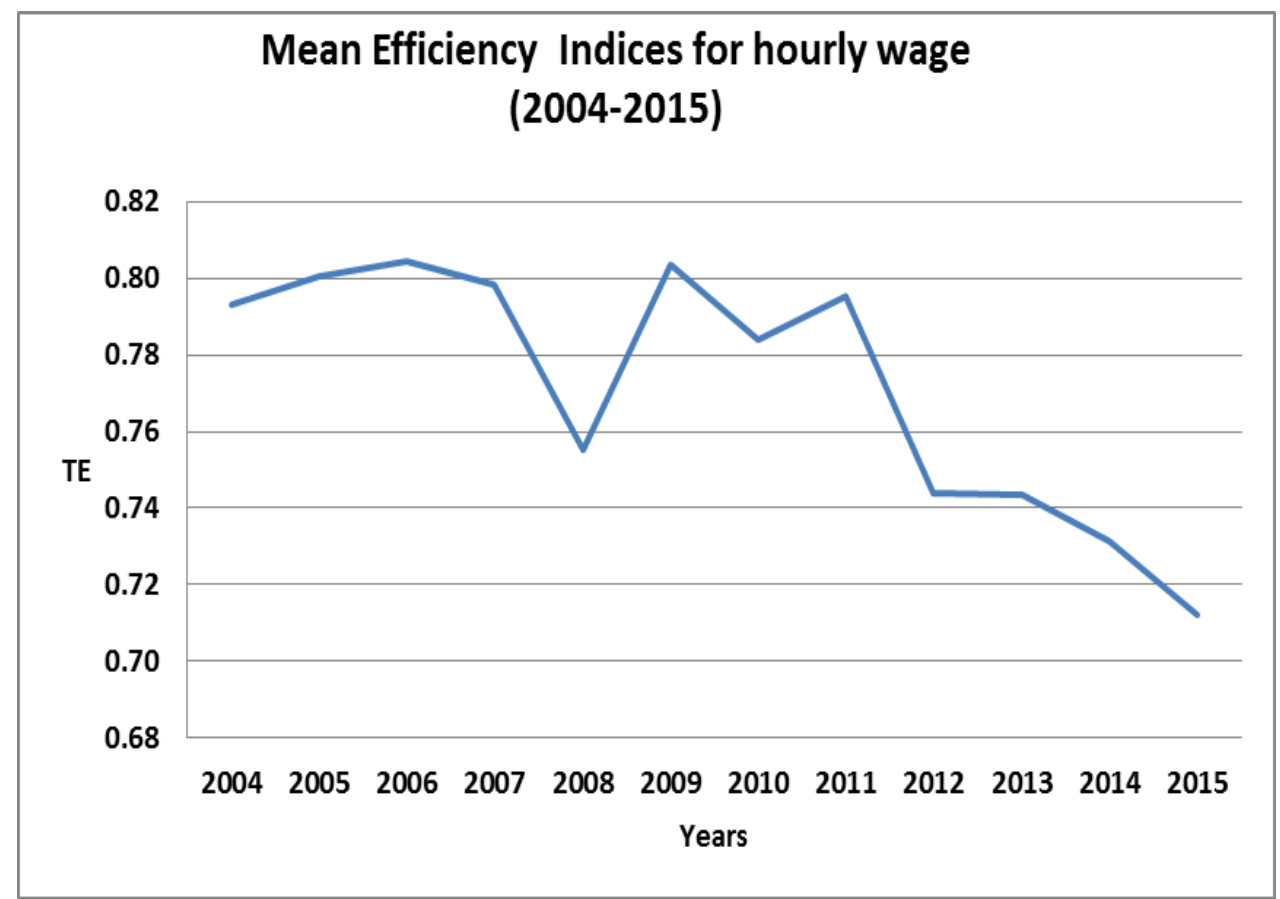

Source: Own elaboration 


\section{Figure III}

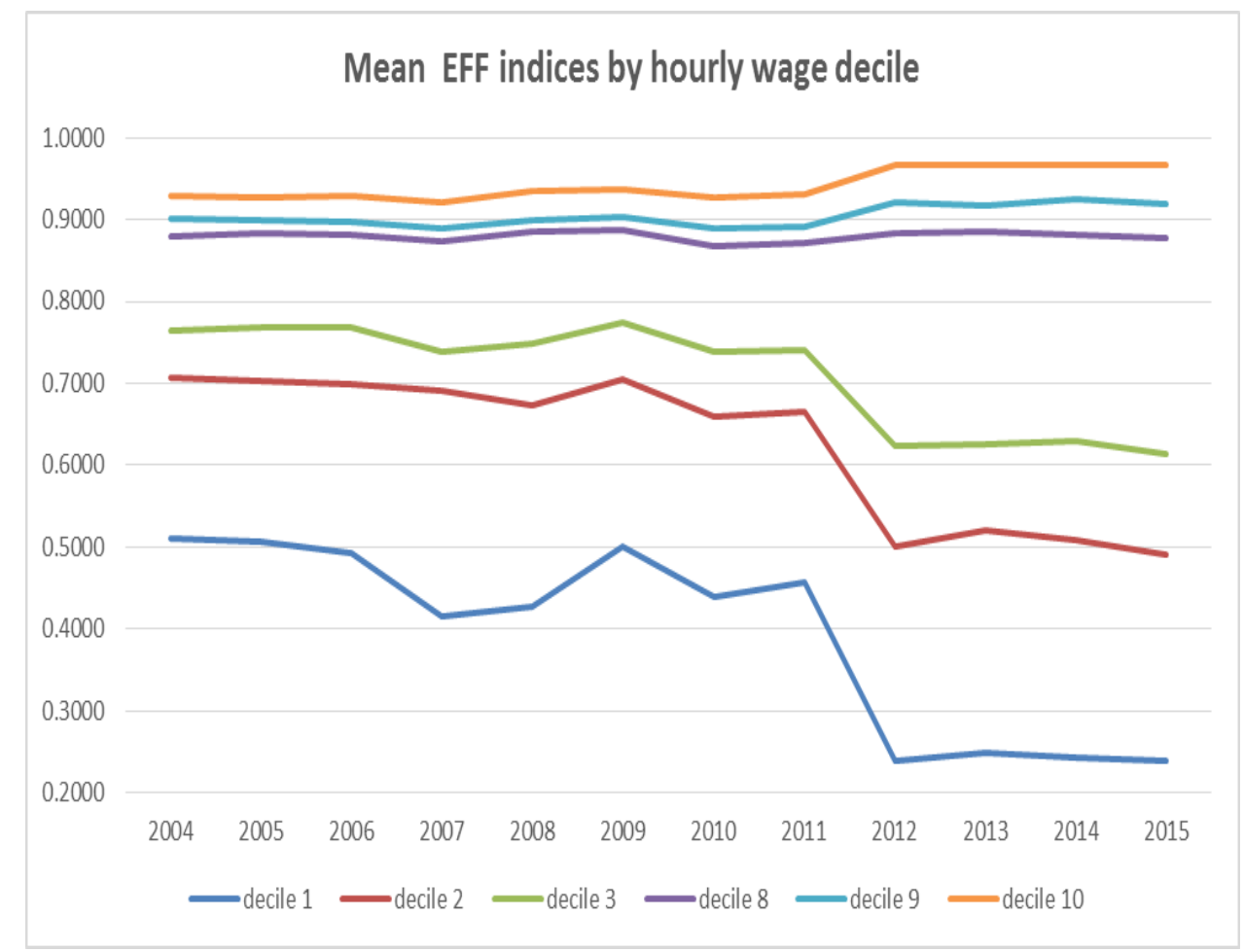

Source: Own elaboration

\section{Figure IV}

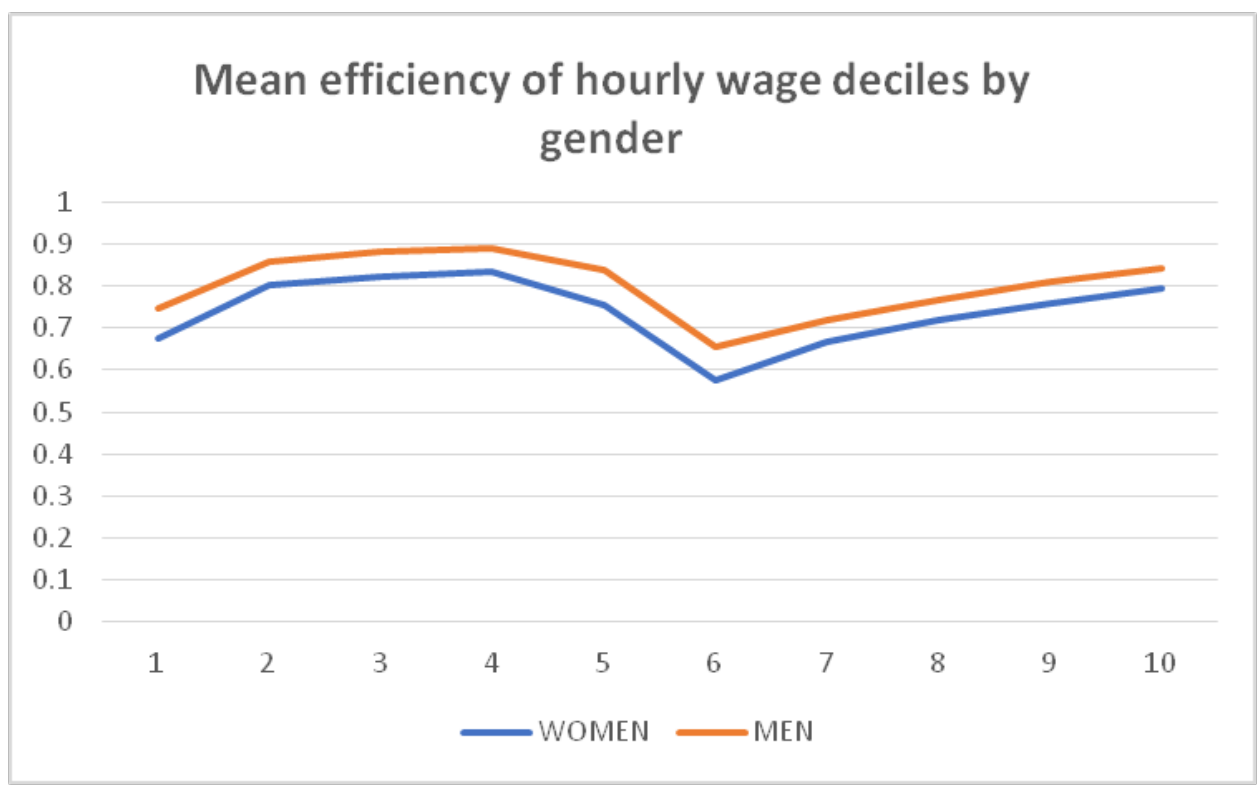

Source: Own elaboration 


\section{Figure V}

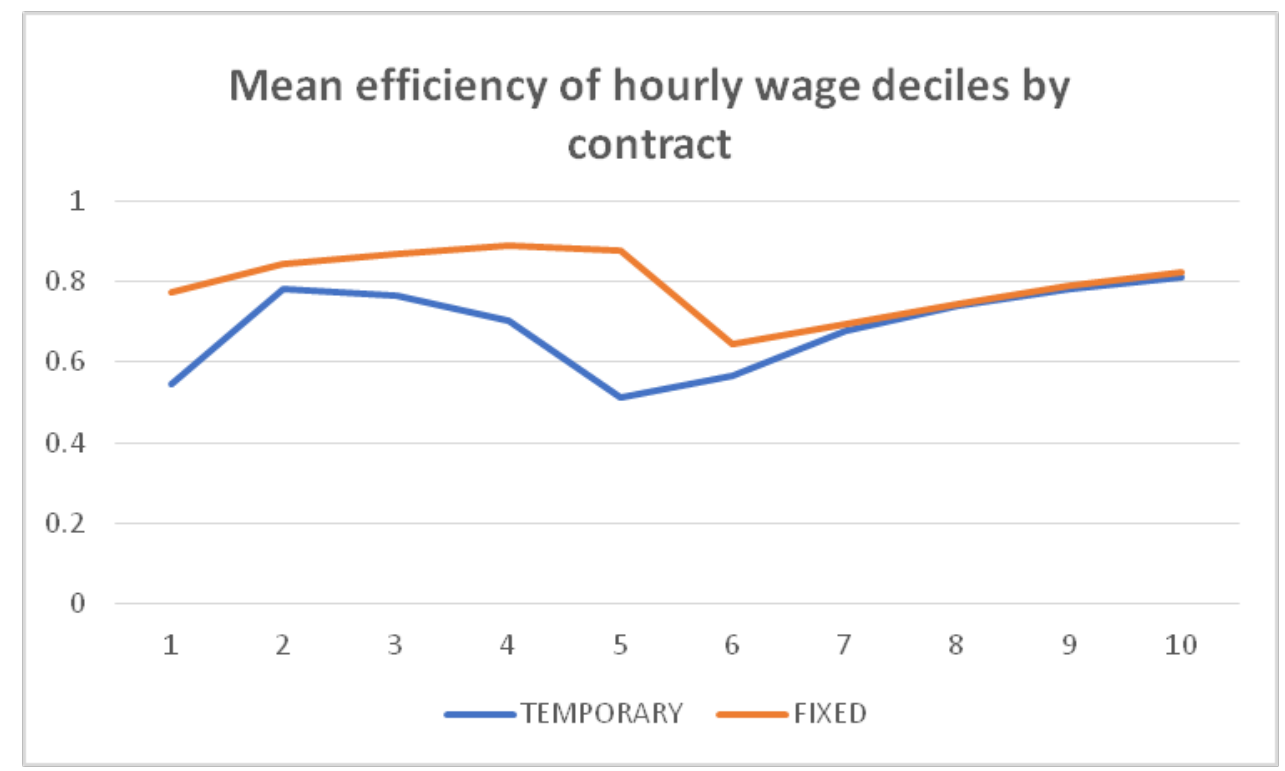

Source: Own elaboration 